Chapter 8

\title{
Mechanical and Acoustic Properties of Magnesium Alloys Based (Nano) Composites Prepared by Powder Metallurgical Routs
}

\author{
Zuzanka Trojanová, Pavel Lukáč, Zoltán Száraz and \\ Zdeněk Drozd
}

Additional information is available at the end of the chapter

http://dx.doi.org/10.5772/57454

\section{Introduction}

Magnesium materials are excellent candidates for structural applications where low weight plays an important role. However, $\mathrm{Mg}$ and its alloys possess low stiffness and strength compared with aluminum alloys. One way to enhance the strength of $\mathrm{Mg}$ is to reinforce it with stronger particles or fibers of the second phase, essentially forming composite microstructures. Composites reinforced with micro-sized particulates of various materials were very often used to enhance the elastic modulus and mechanical properties. Addition of micro-particles, such as $\mathrm{SiC}, \mathrm{Y}_{2} \mathrm{O}_{3}, \mathrm{MgO}, \mathrm{Al}_{2} \mathrm{O}_{3}$ particles and $\mathrm{CNT}$ (carbon nanotubes) into $\mathrm{Mg}$ and $\mathrm{Mg}$ alloys has been shown to improve yield strength, modulus, hardness, fatigue and wear resistance, as well as damping properties and thermal stability (Száraz et.al., 2007, Moll et.al., 2000, Ferkel \& Mordike, 2001, Trojanová et al., 1997). By scaling the particle size down to the nanometer scale, it has been shown that novel material properties can be obtained (Thostenston et al., 2005).

\section{Materials processing}

\subsection{Preparation of $\mathrm{Mg}$ alloys reinforced with $\mathrm{SiC}$ particles}

The AZ91, WE54 and Mg-8Li magnesium alloys reinforced with SiC particles with were processed by a powder metallurgy method. Mixing of the matrix alloys powders with SiC microparticles (mp) was carried out first in an asymmetrically moved mixer with subsequent milling in a ball mill. The powder was capsulated in magnesium containers and extruded at 
$400{ }^{\circ} \mathrm{C}$ using a $400 \mathrm{t}$ horizontal extrusion press. The composite samples were not thermally treated. Microstructure of the as prepared WE54/SiC composite in introduced in Fig. 1a (the micrograph was taken perpendicular to the extrusion direction). SiC $\mathrm{mp}$ are non-uniformly distributed in the matrix; they form in many cases small clusters. The size of sharp bounded more or less uniaxial particles was approximately $9 \mu \mathrm{m}$ and the grain size in the matrix about 3-4 $\mu \mathrm{m}$. Light micrographs and transmission electron micrographs showed no pores in the composite and the binding between $\mathrm{SiC}$ particles and the matrix was perfect. No defects were found in the vicinity of $\mathrm{SiC}$ particles and no chemical reaction at the interface matrix/SiC particles was observed. Microstructure of the $\mathrm{Mg} 8 \mathrm{Li} / \mathrm{SiC}$ composite exhibits a mixture of two phases (hexagonal close packed $\alpha$ phase and body centred cubic $\beta$ phase). In Fig. 2 light $\alpha$ and darker $\beta$ phase are visible together with $\mathrm{SiC}$ particles The $\mathrm{X}$-ray analysis revealed the relation between both phases as $\alpha: \beta=55: 45$. As the grain size the mean value of $5 \pm 2 \mu \mathrm{m}$ was taken from both phases. Resulting materials contained different volume fraction of particles: AZ91 (13 vol. \%), WE53 (13 vol. \%) and Mg8Li (7\% vol. \%).

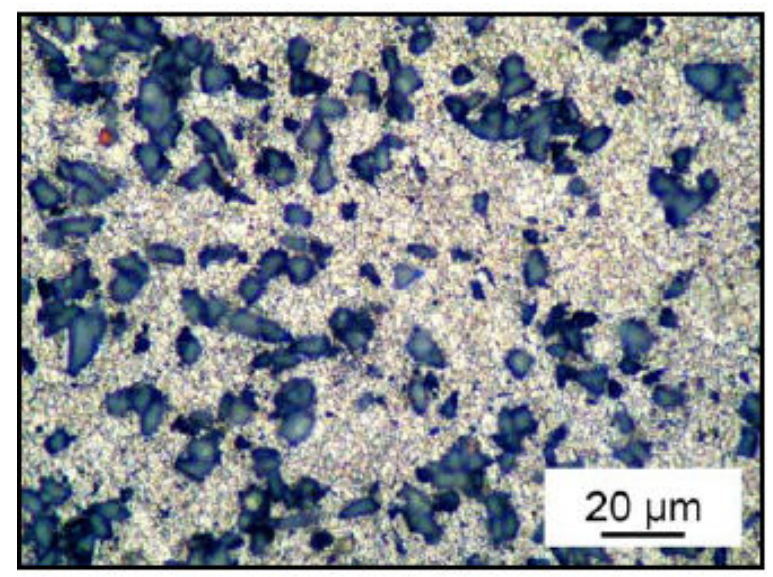

Figure 1. Microstructure of WE54/SiC.

\subsection{Preparation of $\mathrm{Mg}$ based nanocomposites and ultrafine grained materials}

Microcrystalline magnesium ( $\mu-\mathrm{Mg})$ with 3 vol. \% of alumina $\left(\mathrm{Al}_{2} \mathrm{O}_{3}\right)$ nanoparticles (np) $(\mu-\mathrm{Mg}$ $\left.+3 \mathrm{nAl}_{2} \mathrm{O}_{3}\right), \mu-\mathrm{Mg}$ with 3 vol.\% of zirconia np $\left(\mu-\mathrm{Mg}+3 \mathrm{ZrO}_{2}\right)$ and microcrystalline $\mathrm{Mg}(\mu-\mathrm{Mg})$ were studied. Micro-scaled Mg powder having a particle diameter of about $40 \mu \mathrm{m}$ was prepared by gas atomisation of a high purity Mg melt in Ar atmosphere containing 1\% oxygen for powder passivation. Both alumina and zirconia powders with a mean particle size of 14 $\mathrm{nm}$ were prepared by evaporation with the pulsed radiation of a $1000 \mathrm{~W} \mathrm{Nd}$ :YAG laser and subsequent condensation of the laser-induced vapor in a controlled aggregation gas. The preparation method of $n p$ is described elsewhere (Naser et al., 1997, Ferkel \& Mordike, 2001). The $\mathrm{Mg}$ powder was mixed with ceramic $\mathrm{np}$ in an asymmetrically moved mixer for $8 \mathrm{~h}$. The 


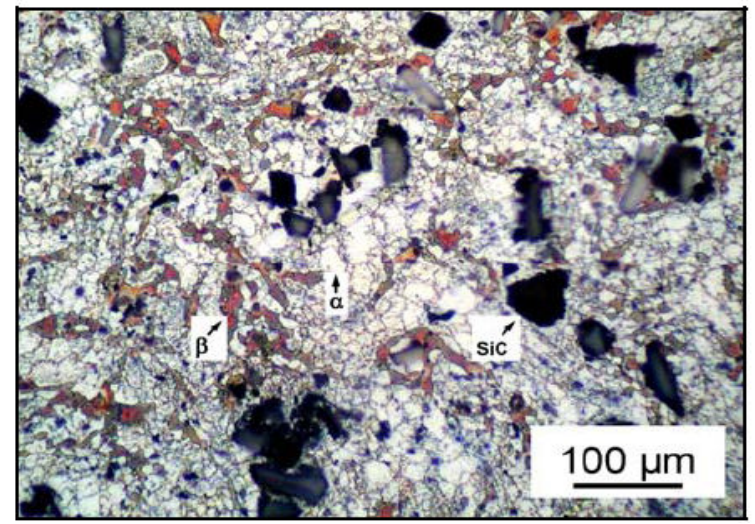

Figure 2. SEM micrograph of Mg8Li/SiC.

powder mixture was then milled together for $1 \mathrm{~h}$ in a planetary ball mill. Mixture was subsequently pre-compressed followed by hot extrusion at a temperature of $350{ }^{\circ} \mathrm{C}$ under a pressure of $150 \mathrm{MPa}$. After extrusion, the originally more or less equiaxial grains changed into elliptical grains with the long axis parallel to the extrusion direction. The grain size in the cross section was about $3 \mu \mathrm{m}$ and in the extrusion direction $10 \mu \mathrm{m}$. The distribution of the $\mathrm{np}$ was not homogenous. The np or their agglomerates were located mainly along the grain boundaries of the resultant material. The transmission electron microscopical inspection revealed that only few particles were distributed within grains. Similar procedure was used for preparation of $\mu-\mathrm{Mg}$ with 3 vol. $\%$ of alumina microparticles $\left(\mu-\mathrm{Mg}+3 \mu \mathrm{Al}_{2} \mathrm{O}_{3}\right)$

Details of the preparation of the UFG-Mg and nanocomposite (nc) with the 3 vol. \% of graphite nanopartiles (Gr np) (UFG-Mg+3nGr) was similar to the nc with the ceramic np. The microscaled $\mathrm{Mg}$ powder was prepared by gas atomisation of a high purity magnesium melt with argon atmosphere containing $1 \%$ oxygen for powder passivation. The Mg-powder had a median particle diameter of about $40 \mu \mathrm{m}$. The graphite powder used had a median particle size of $1-2 \mu \mathrm{m}$. The $\mathrm{Mg}$ powder was mixed with 3 vol. $\%$ of graphite powder in an asymmetrically moving mixer for $8 \mathrm{~h}$. The powder mixtures were then milled for $8 \mathrm{~h}$ at $200 \mathrm{rpm}$ in the planetary ball mill (Retsch, PM400) in a sealed argon atmosphere. The milling vessel of $500 \mathrm{ml}$ volume was made of corundum and the milling balls ( $11 \mathrm{~mm}$ diameter) were made of hardened steel (100Cr6). The weight ratio of ball-to-powder was 10:1. The composite was encapsulated in an evacuated $\mathrm{Mg}$ container $\left(70 \mathrm{~mm}\right.$ in diameter), degassed at $350{ }^{\circ} \mathrm{C}$, and extruded by the preheated $\left(350^{\circ} \mathrm{C}\right) 400 \mathrm{t}$ horizontal extrusion press (outlet $14 \mathrm{~mm}$ ). Analyses of the extruded material in an optical spark analyser (Spectrolab, Spectro Analytical Instruments) reveal no contamination of the composite by e.g. Fe from the extruder tools or milling balls, or Al from milling vessel (Ferkel, 2003). The mean grain size of specimens used was estimated, using transmission electron microscopy and X-ray profile analysis, to be about 150-200 nm. TEM of the UFG-Mg+3nGr is shown in Fig. 3. 


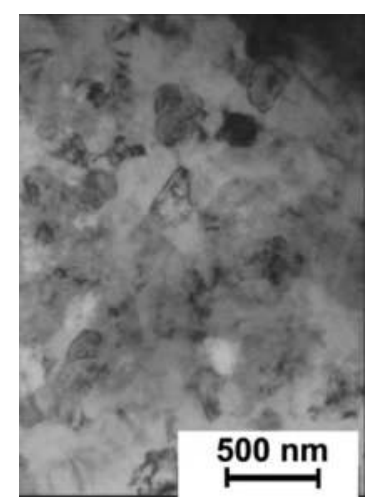

Figure 3. TEM of UFG-Mg with 3 vol\% Gr.

\section{Mechanical properties}

\subsection{Composites reinforced with $\mathrm{SiC}$ microparticles}

\subsubsection{Compressive stress-strain curves}

Deformation tests were carried out at temperatures between room temperature and $450{ }^{\circ} \mathrm{C}$ using an INSTRON testing machine. Cylindrical specimens of $8 \mathrm{~mm}$ diameter and $12 \mathrm{~mm}$ length were used for deformation tests performed in compression. The tensile specimens exhibited a gauge length of $10 \mathrm{~mm}$ and gauge diameter of $6 \mathrm{~mm}$. Both samples were machined with a stress axis parallel to the extrusion direction. The strain rate sensitivity parameter $m$ has been estimated by the abrupt strain rate changes (SRC) method. SRC tests and tensile tests with a constant strain rate ( $\dot{\varepsilon}=$ const.) were performed at temperatures from 300 to $450{ }^{\circ} \mathrm{C}$. Temperature in the furnace was kept with an accuracy of $\pm 1^{\circ} \mathrm{C}$. Fig. 4 shows the compressive true stress-strain curves obtained for $\mathrm{AZ} 91 / \mathrm{SiC}$ composite deformed at various temperatures. Samples were deformed either to fracture or at higher temperatures to predetermined strains. The stress-strain curves obtained at temperatures up to $150{ }^{\circ} \mathrm{C}$ exhibit the small hump at the beginning of deformation. Curves at temperatures higher than $150{ }^{\circ} \mathrm{C}$ are very flat; the maximum stress is achieved at lower strains. Similar stress strain curves obtained in compression for WE54+13\%SiC composite at various temperatures are introduced in Fig. 5 . The stressstrain curves obtained at higher temperatures have a flat character. The temperature influence on the strain hardening of the composite is well visible. The yield stress decreases with increasing temperature very slowly up to $200{ }^{\circ} \mathrm{C}$. At temperatures higher than $200{ }^{\circ} \mathrm{C}$ both characteristic stresses (the compression yield stress and the compression strength) decrease substantially. It can be concluded that the thermal stability of the composite is up to $200{ }^{\circ} \mathrm{C}$ very good. The stress-strain curves estimated for $\mathrm{Mg}-8 \mathrm{Li} / \mathrm{SiC}$ composite at various tempera- 
tures are shown in Fig. 6. A continuous decrease in characteristic stresses can be seen from Fig. 6.

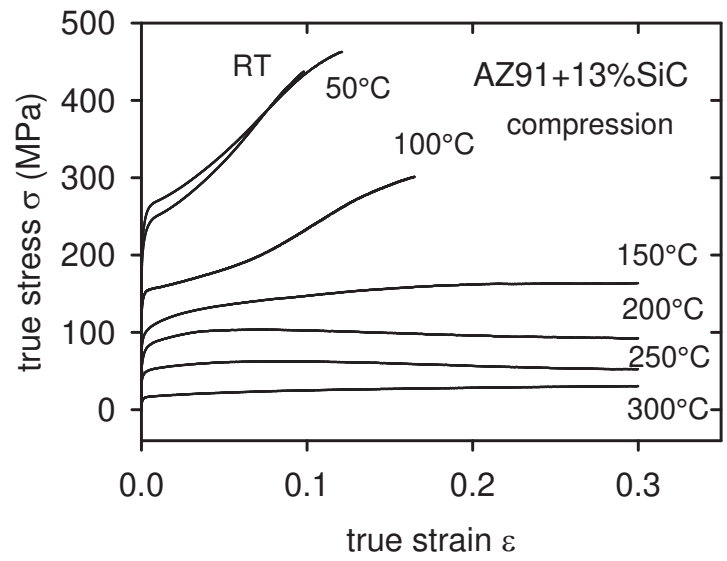

Figure 4. Compressive true stress-true-strain curves obtained for AZ91/SiC samples.

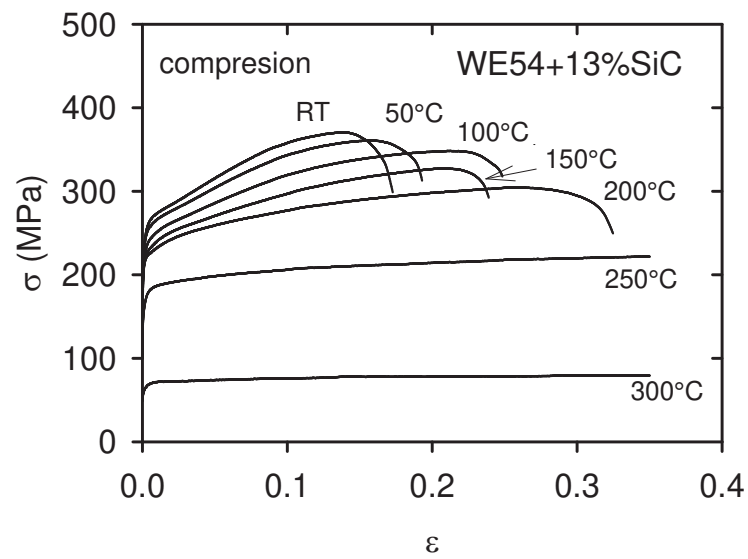

Figure 5. Compressive true stress-true strain curves obtained for WE54/SiC samples.

The compression yield stresses (CYS) estimated as the proof stresses at a strain of 0.002 are introduced in Table 1 together with the ultimate compression strength values (UCS). Three characteristic temperatures have been chosen. 


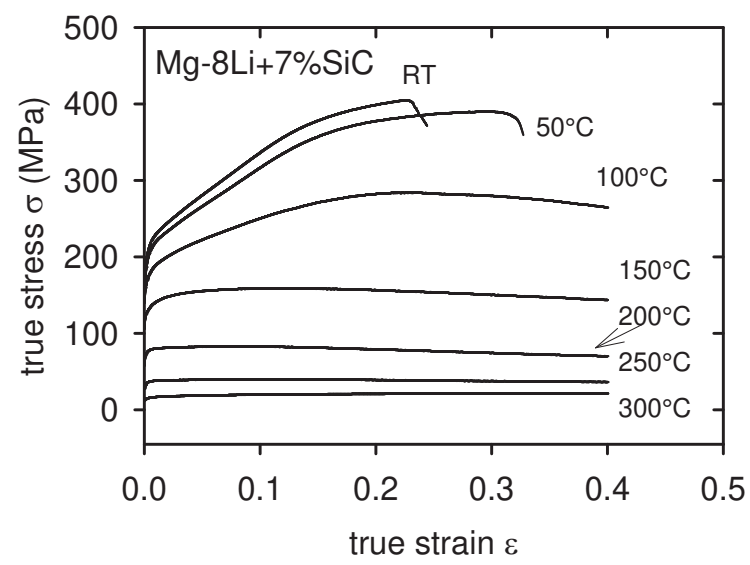

Figure 6. Compressive true stress-true strain curves obtained for Mg8Li.

\begin{tabular}{ccccccc}
\hline & \multicolumn{2}{c}{ RT } & \multicolumn{2}{c}{$\mathbf{1 5 0}{ }^{\circ} \mathrm{C}$} & \multicolumn{2}{c}{$\mathbf{3 0 0}{ }^{\circ} \mathrm{C}$} \\
\hline & CYS(MPa) & UCS(MPa) & CYS(MPa) & UCS(MPa) & CYS(MPa) & UCS(MPa) \\
\hline AZ91/13SiC & 222.5 & 437 & 98 & 163.8 & 15.6 & 30.6 \\
\hline WE54/13SiC & 245.6 & 370 & 219.7 & 327.4 & 64.5 & 81.6 \\
\hline Mg8Li/7SiC & 198.3 & 404.6 & 126.5 & 159 & 14.8 & 22 \\
\hline
\end{tabular}

Table 1. Values of the yield stress and the ultimate compression strength estimated for three temperatures.

Table 1 shows a rapid decrease in the characteristic stresses obtained for AZ91/SiC and Mg8Li/ $\mathrm{SiC}$ composites, while the decrease in the case of WE54/SiC composite is not so significant. This behaviour is very probably due to the presence of rare earth elements in the alloy. Rare earth elements form thermally stable precipitates situated in the grain boundaries. These grain boundary networks are also the reason for the good creep resistance.

TEM of the non-deformed WE54 composite sample and the WE54/SiC sample deformed in compression at $50{ }^{\circ} \mathrm{C}$ are shown in Figs. 7 and 8, respectively. TEM investigation showed that presence cuboidal particles which were identified as $\mathrm{Mg}_{12} \mathrm{NdY}$ precipitates. Many twins are a common feature for both non-deformed as well as deformed material. Grains in as-received material are well visible in Fig. 8. Thin twins, within single grains, are parallel to each other and quite narrow. Sometimes twins are extended through the grain boundary, causing a grain boundary deflection. The role of twinning is well known in deformation of hcp lattice alloys. Twinning is an important deformation mode of $\mathrm{Mg}$ alloys. It reorients the slip planes in order to relax stress concentrations and enhances multiple slip. Thin twins, often appearing in the form of parallel groups, where detected in compressed material (Ion et al., 1982). Another feature in the microstructure of the deformed composites is a high dislocation density. 
Dislocations in many cases form pile ups and tangles (see Fig. 8). Significant amount of rectangular shape fine particles was estimated distributed within the grains.

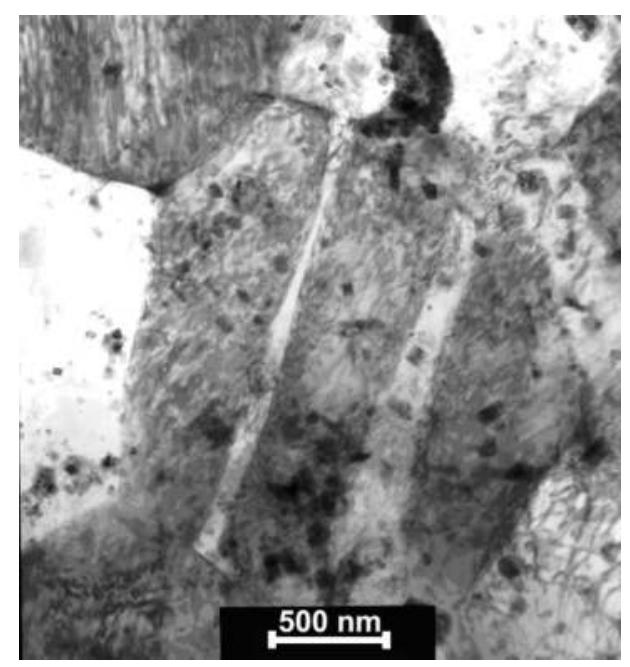

Figure 7. Twins and precipitates in non-deformed composite. Dislocations in the right bottom corner are visible.

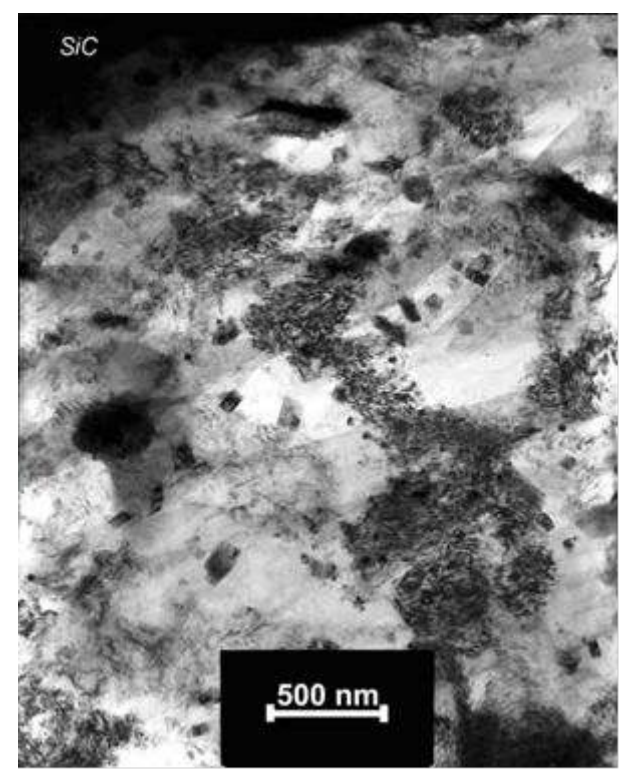

Figure 8. TEM of the WE54/SiC sample deformed at $50^{\circ} \mathrm{C}$. SiC particle is situated in the top left corner of the picture. 
In order to obtain more detailed information concerning the deformation mechanism(-s) occurring in particle reinforced magnesium alloys based composites, acoustic emission (AE) was used. AE stems from transient elastic waves which are generated within the material during deformation due to sudden localized and irreversible structure changes like dislocation glide and twinning, which may be considered as the main deformation mechanisms in $\mathrm{Mg}$ and its alloys due to their hexagonal crystal structure. WE54/SiC samples were deformed in compression at room temperature. The engineering stress- time plots together with the time variation of the AE count rates are shown in Fig. 9. Two AE maxima were observed. The observed $\mathrm{AE}$ maximum at the onset of plastic deformation is connected with the yield point $(\mathrm{CYS} \cong 280 \mathrm{MPa})$ and it may be ascribed to the stochastic $\{10 \overline{1} 2\}\langle 10 \overline{1} 0\rangle$ primary twin formation in the grains unfavourably oriented for the basal slip during the very early stage of plastic deformation. These twins reorient the original lattice on $86.3^{\circ}$ and the subsequent straining may continue by the basal slip and secondary twinning.

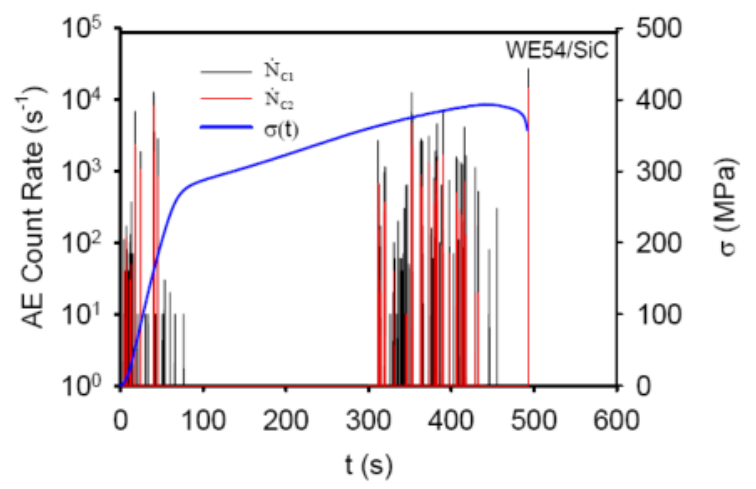

Figure 9. Deformation curve and AE count rate for WE54/SiC composite obtained at ambient temperature.

New twins were observed in the deformed microstructure (Fig. 10). Slim twins were observed also by the TEM as demonstrated in Fig. 8. These twins (and also dislocations visible in Fig. 8) arose very probably during extrusion of the powder material. Possible dislocation contribution to the AE signal is very probably marginal due to small grain sizes. The slip length of dislocations is very short (see dislocation tangles in the left bottom corner of the micrograph 8) and therefore the probability of pile ups formation is also very low. The mobility of dislocations is further limited due to the presence of small cuboidal particles visible in Fig. 7 and 8 . The AE signal detected at the time point of $\sim 310 \mathrm{~s}$ and onwards is discontinuous, and its sources may be ascribed to damage processes. Specifically, with the addition of the reinforcing phase, the geometrically necessary dislocations are generated to accommodate the plastic mismatch in the matrix. The stress concentrations in the vicinity of the reinforcing SiC particles may achieve their critical value and a breakage of particles and/or a release of cracks (decohesion) between the matrix and particles can occur. Both processes are considered as strong sources of the AE signal. The broken $\mathrm{SiC}$ particles and also cracks in the vicinity of 
particles were observed at the polished surface of the sample deformed to failure (see Fig. 11). Two main mechanisms were detected during plastic deformation: breakage of particles and decohesion in the particle-matrix interface. Based on these results we may consider localisation of the plastic deformation and fracture of the sample if the number of broken particles achieves its critical value.

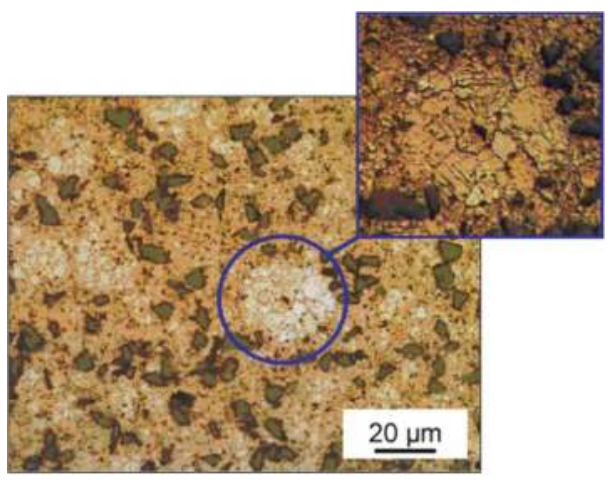

Figure 10. Light micrographs showing new twins formed during plastic deformation in the WE54/SiC sample.

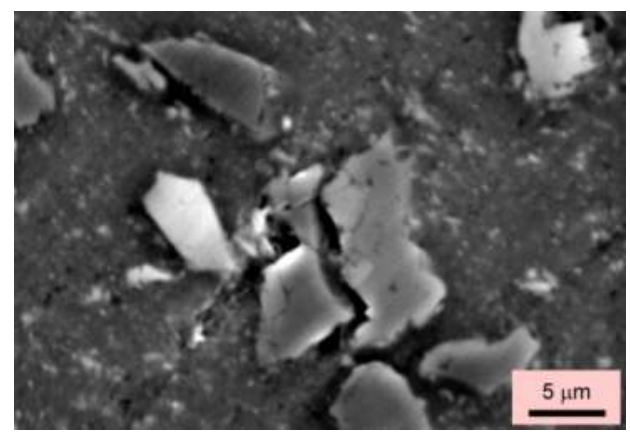

Figure 11. Scanning electron micrograph showing broken particles on the surface of the deformed WE54/SiC sample. Decohesion between the matrix and particles is also visible.

\subsubsection{High temperature properties estimated in tension}

The tensile true stress-strain curves estimated for WE54/SiC samples at a strain rate of $2.8 \times 10^{-4} \mathrm{~s}^{-1}$ and various temperatures are shown in Fig. 12. A significant work hardening was obtained at temperatures up to $150^{\circ} \mathrm{C}$. A considerable decrease in the flow stress was observed after increasing the temperature from 250 to $300{ }^{\circ} \mathrm{C}$. Curves obtained at temperatures higher than $250{ }^{\circ} \mathrm{C}$ have a flat character. It indicates new deformation process(-es) taking place at temperatures higher than $250{ }^{\circ} \mathrm{C}$. Small grain sizes of powder metallurgically prepared 
materials indicate possibility of superplastic deformation. To check this eventuality, SRC tests were performed at temperatures from 350 to $450{ }^{\circ} \mathrm{C}$. The values of the strain rate sensitivity $m$ estimated for various strain rates and temperatures are given in Fig. 13. The strong strain rate dependence of the $m$-parameter is obvious from the picture. With increasing temperature the dependence is shifted to higher strain-rates. However, the $m$ parameter slightly increases with temperature; the maximum values are in the vicinity of 0.3 as it is obvious from Table 2.

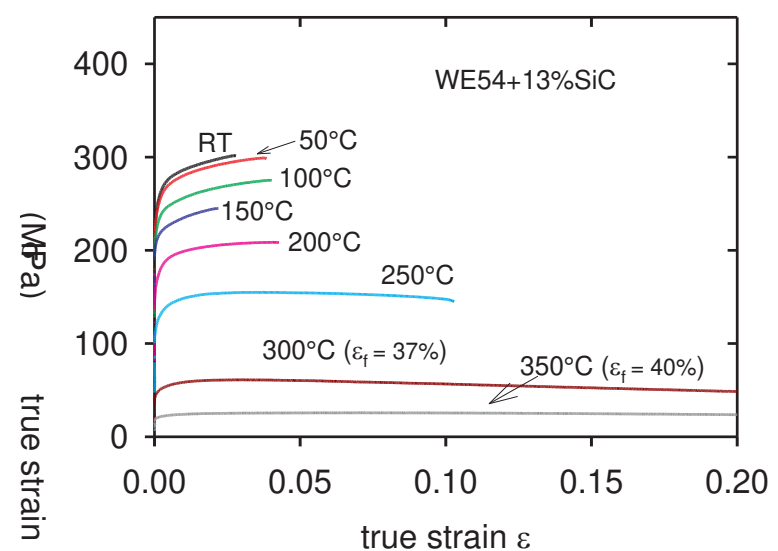

Figure 12. Tensile true stress-true strain curves estimated for WE54/SiC composite at various temperatures.

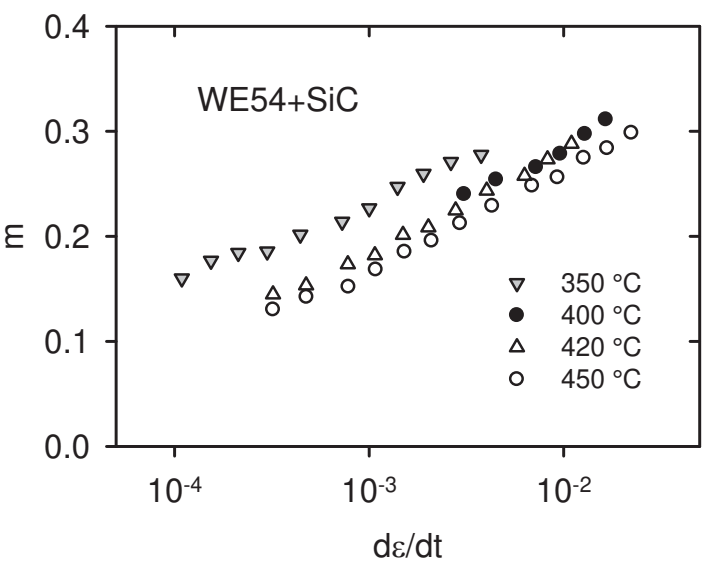

Figure 13. Strain rate dependence of $\mathrm{m}$-parameter estimated at various temperatures. 
The maximum recorded elongation to failure was $99 \%$, which shows an evidence of the enhanced plasticity, nevertheless this value remains below the bottom limit for superplastic region. SEM micrograph of the sample exhibiting the highest elongation is shown on Fig. 14 documenting the microstructure after deformation at $450{ }^{\circ} \mathrm{C}$. Numerous cavities formed during the high temperature deformation are visible in Fig. 14. The cavitation primarily occurred at the reinforcement/matrix interfaces, which are the preferential sites for the nucleation of cavities. The density of cavities was higher near the fracture surface where elongated cavities were found. Since many of these cavities were fairly large, it is reasonable to assume that growth and subsequent coalescence and interlinkage of the cavities led to the premature failure.

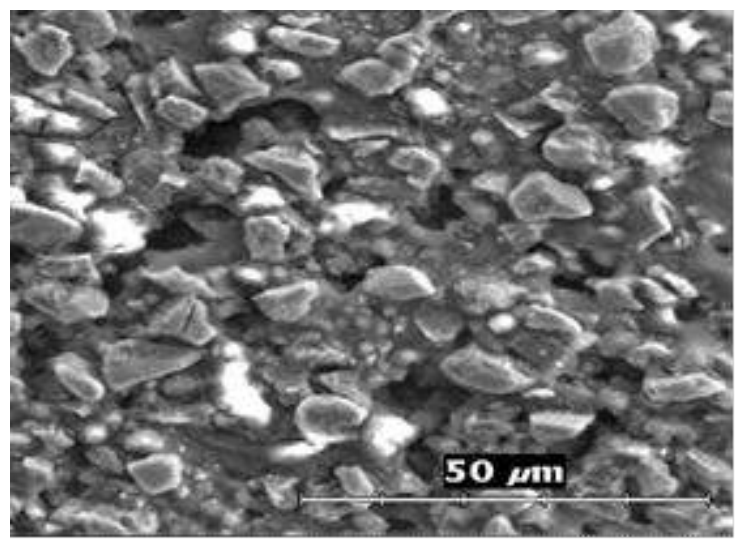

Figure 14. SEM micrograph showing cavities formed during high temperature deformation.

\begin{tabular}{llll}
\hline & $\mathrm{m}_{\max }$ & $\dot{\varepsilon}\left(\mathbf{s}^{-1}\right)$ & $\boldsymbol{\varepsilon}_{\mathrm{f}}(\%)$ \\
\hline $350^{\circ} \mathrm{C}$ & 0.28 & $4 \times 10^{-3}$ & 66 \\
\hline $420^{\circ} \mathrm{C}$ & 0.30 & $2 \times 10^{-2}$ & 95 \\
\hline $450^{\circ} \mathrm{C}$ & 0.29 & $5 \times 10^{-2}$ & 99 \\
\hline
\end{tabular}

Table 2. Maximum values of $m$-parameter and elongation to failure estimated for three temperatures and corresponding strain rates.

Similar study was performed for the $\mathrm{Mg} 8 \mathrm{Li} / \mathrm{SiC}$ samples. The strain rate sensitivity values $m$, obtained in tension using SRC method at temperatures 200,250 and $300{ }^{\circ} \mathrm{C}$ are introduced in Fig. 15. It is obvious that the $m$-values increased with increasing deformation temperature and the dependence was shifted to the higher strain rates. While at $200{ }^{\circ} \mathrm{C}$ the maximum of $m$ was reached at $\dot{\varepsilon}=4 \times 10^{-5} \mathrm{~s}^{-1}$, at a temperature of $300^{\circ} \mathrm{C}$ the maximum laid in the vicinity of the strain rate $\dot{\varepsilon}=6 \times 10^{-4} \mathrm{~s}^{-1}$. The maximum value of $m$ estimated at $300^{\circ} \mathrm{C}$ exhibited 0.46 , which is close to a value of 0.5 , considered as an optimal value for the superplasticity. The maximum value 
of $m=0.3$ at $200{ }^{\circ} \mathrm{C}$ and all values of $m$ estimated at temperatures higher for all strain rates were in the region enclosing the superplastic behaviour. The maximum ductility $A=110 \%$ was found at $300{ }^{\circ} \mathrm{C}$ and at a strain rate of $6 \times 10^{-4} \mathrm{~s}^{-1}$, which correspond to the maximum of the strain rate sensitivity $m=0.46$. Despite of relatively high values of the strain rate sensitivity $m$, the achieved ductility was only at the onset of the superplastic region.

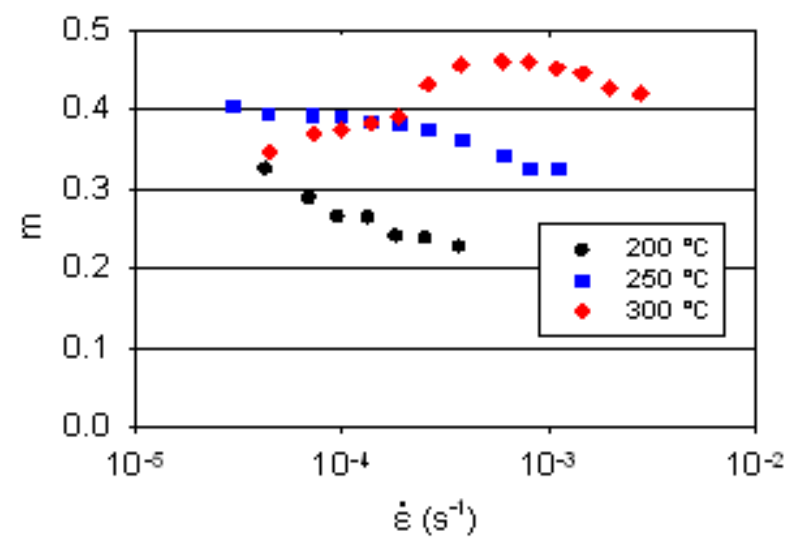

Figure 15. Strain rate dependence of the strain rate sensitivity parameter estimated for Mg8Li/SiC.

The observed cavities formation after high temperature deformation in WE54/SiC and Mg8Li/ $\mathrm{SiC}$ composites indicates the presence of some diffusion process. The activation energy $Q$ of such rate controlling is given by the relationship (Langdon, 1994):

$$
\dot{\varepsilon}=\frac{A D_{0} G b}{k T}\left(\frac{b}{d}\right)^{p}\left(\frac{\sigma}{G}\right)^{n} \exp \left(-\frac{Q}{R T}\right),
$$

where $\dot{\varepsilon}$ is steady-state deformation rate, $\mathrm{A}$ is a dimensionless constant, $d$ is the grain size, $\sigma$ is the applied stress, $p$ is the grain size exponent, $n=1 / m$ is the stress exponent and $D_{0}$ is the pre-exponential factor; $k T$ has its usual meaning and $R$ is the gas constant. The activation energy $Q$ is a slope of the plot $\sigma / G$ vs $1 / T$ (when $\dot{\varepsilon} T / G$ is constant):

$$
Q=\frac{1}{m} R \frac{\Delta(\ln \sigma / G)}{\Delta(1 / T)}
$$

The activation energy was estimated using relationship (2) for both composites to be $Q$ (WE54/ $\mathrm{SiC})=114 \mathrm{~kJ} / \mathrm{mol}$. The activation energy for the volume diffusion is $135 \mathrm{~kJ} / \mathrm{mol}$ and for the grain boundary diffusion $92 \mathrm{~kJ} / \mathrm{mol}$ (Frost \& Ashby, 1982). Comparing to an experimental value of $114 \mathrm{~kJ} / \mathrm{mol}$ (using rule of mixture), we may conclude that the measured activation energy 
consists of approximately 50\% volume and 50\% grain boundary diffusion. Using estimated values of $m$, the activation energy for $\mathrm{Mg} 8 \mathrm{Li} / \mathrm{SiC}$ composite was found (for the high $\mathrm{m}$ region) $\mathrm{Q} \approx 87 \mathrm{~kJ} / \mathrm{mol}$. According to binary Mg-Li diagram (Nayeb-Hashemi et al., 1984), the Mg-8Li alloy at $300{ }^{\circ} \mathrm{C}$ consists of equilibrium $\alpha$ phase and $\beta$ phase whose chemical composition are 5.7 $\mathrm{Li}$ and $11 \mathrm{Li}$, respectively. Owing to higher mobility of $\mathrm{Li}$ in $\beta$ phase the Li content in $\beta$ phase decreases while in the $\alpha$ phase increases and the volume fraction of the $\alpha$ phase increases at the expense of $\beta$ phase. Due to grain boundary migration caused by atomic mobility, the grain size of $\alpha$ phase increases.

Experimentally estimated value of the activation energy $Q=87 \mathrm{~kJ} / \mathrm{mol}$ indicates that the main rate controlling mechanism is the grain boundary sliding accommodated with the grain boundary diffusion with the small contribution of the lattice diffusion. The successive grain growth increases the grain size in the $\alpha$ phase. The diffusion accommodation of the grain boundary sliding is more difficult, which implies cavities formation.

Observed formation and growth of cavities relaxes the stress concentration caused at the particles on the sliding grain boundaries. Cavities, created by vacancy clustering, may nucleate if the stress concentration is not relieved sufficiently rapidly. Local tensile stress caused by sliding at interfaces may be written in the form (Mabuchi \& Higashi, 1999):

$$
\sigma_{\text {slid }}=\frac{0.92 k T d_{p} \dot{\varepsilon} d V_{f}}{\Omega D_{L}\left(1+5 \frac{\delta D_{G B}}{d_{p} D_{L}}\right)}
$$

where $d_{p}$ is the particle diameter, $\dot{\varepsilon}$ is the strain rate, $d$ is the grain size, $D_{L}$ is the lattice diffusion and $D_{G B}$ is the grain boundary diffusion coefficient, $\delta$ is the grain boundary width, $\Omega$ is the atomic volume. $V_{f}$ is the volume fraction of particles and $k T$ has its usual meaning. The insufficiently accommodated grain boundary sliding process is the reason for cavitation and early failure of samples.

Based on our results of mechanical tests, microstructural observations and the analysis of the AE signal occurring during plastic deformation, we may conclude that the deformation processes in the powder metallurgically prepared magnesium alloys based composites are different at lower and higher temperatures. At lower temperatures (below about $150{ }^{\circ} \mathrm{C}$ ), the deformation processes have following main characteristics:

i. Small grain size - several micrometers - is a typical feature of the microstructure.

ii. Early stages of the compressive plastic deformation are realised by twinning accommodated with the dislocation glide;

iii. Twin boundaries are impenetrable obstacles for the dislocation motion and contribute to a significant hardening at lower temperatures;

iv. Breakage of particles and decohesion in the particle-matrix interfaces cause localisation of plastic deformation and failure of materials; 


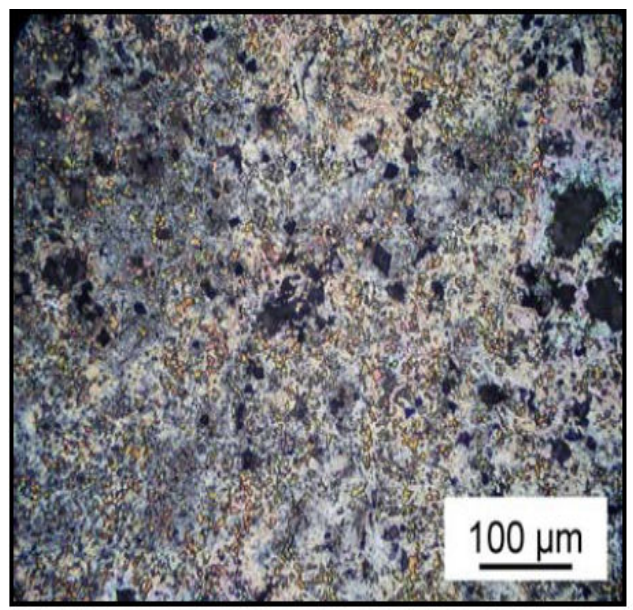

a)

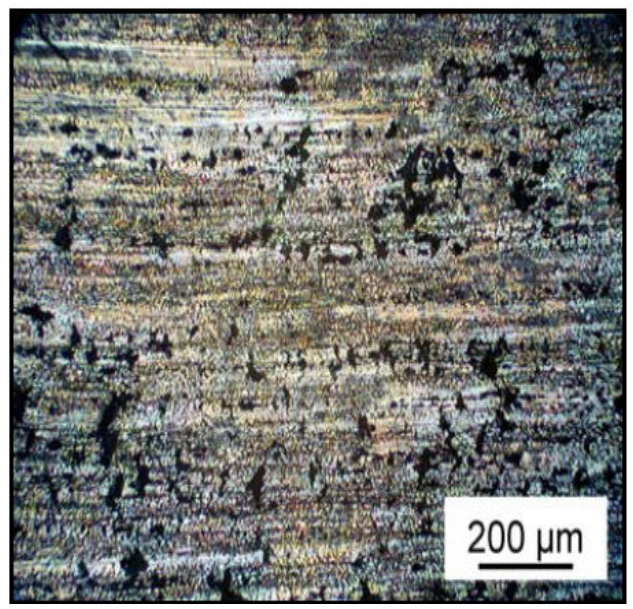

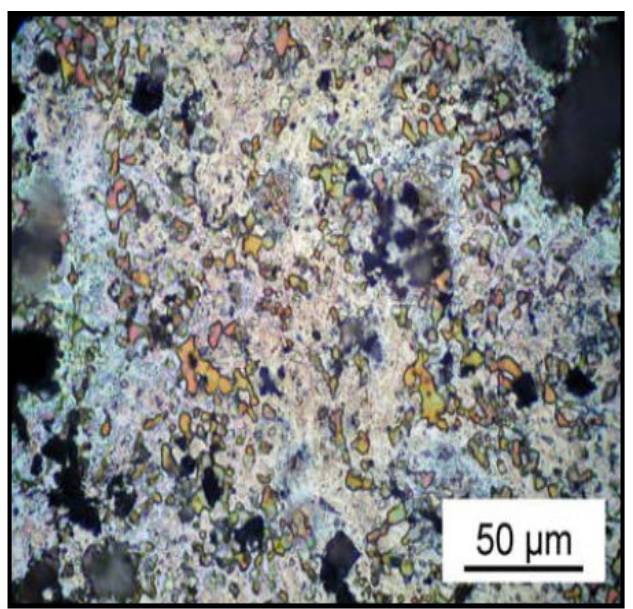

b)

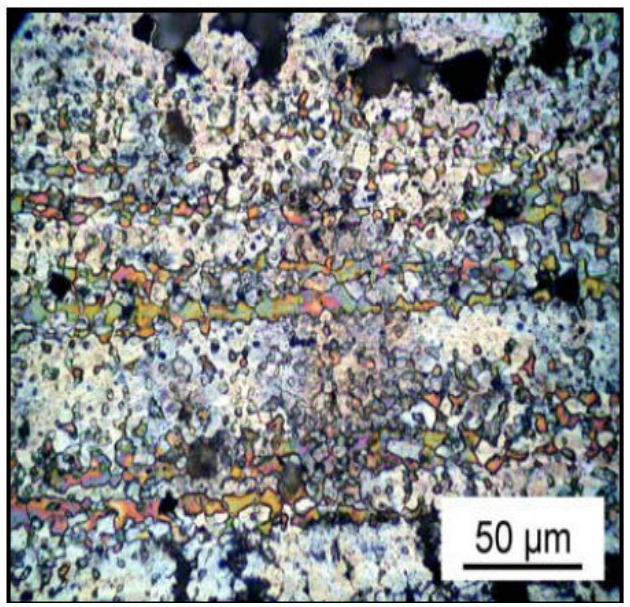

Figure 16. Light micrograph of Mg8Li/SiC composite after deformation at $300{ }^{\circ} \mathrm{C}$ and strain rate $\left.\left.6 \times 10^{-4} \mathrm{~s}^{-1}, \mathrm{a}\right), \mathrm{b}\right) \mathrm{cross}$ section, c), d) longitudinal section.

Although the grain size of composites exhibiting 3-5 $\mu$ m indicated a possibility of the occurrence of the structural superplasticity, only enhanced plasticity was estimated at higher temperatures. This fact has following reasons:

i. $\quad$ The values of the strain rate sensitivity parameter reached $m=0.3-0.5$;

ii. The grain boundary sliding is the significant mechanism operating at higher temperatures; 
iii. The stress concentrations formed at the particles on the sliding grain boundaries are the reason for the cavity formation.

iv. Growth and subsequent coalescence and interlinkage of the cavities led to the premature failure of composites.

\subsection{Stress-strain curves of magnesium micro- and nanocomposites}

\subsubsection{Microcrystalline magnesium reinforced with ceramic microparticles and nanoparticles}

True stress-true strain curves obtained for microcrystalline $\mathrm{Mg}$ reinforced with alumina microparticles are introduced in Fig. 17a for tension and 17b for compression. A substantial difference between shapes of curves measured in tension and compression are visible. Similar curves were obtained also for microcrystalline $\mathrm{Mg}$ reinforced with alumina and zirconia $\mathrm{np}$ as it follows from Figs 18a,b and 19 a,b. It can be seen that the flow stress decreases as the test temperature is increasing. Substantial differences between curves obtained in tension and compression are obvious comparing Fig. 18a,b and 19a,b. While the curves measured in tension are mostly flat (for nc with alumina np at a temperature of $100^{\circ} \mathrm{C}$ and higher), the curve estimated in compression exhibit local maxima: for $\mu-\mathrm{Mg}+3 \mathrm{Al}_{2} \mathrm{O}_{3}$ at $100{ }^{\circ} \mathrm{C}$ and for $\mu-\mathrm{Mg}+3 \mathrm{ZrO}$ at room temperature and $100{ }^{\circ} \mathrm{C}$. The main deformation mode in magnesium is the basal slip - glide of $<\mathrm{a}>$ dislocations. The secondary conservative slip may be realised by the motion of $<\mathrm{a}>-$ dislocations on prismatic and pyramidal planes of the first order. The basal $<a>$ dislocations may react with the pyramidal $<\mathrm{c}+\mathrm{a}>$ dislocations. Different dislocation reactions may produce both sessile and glissile dislocations (Trojanová et al., 2011). Production of sessile dislocations increases the density of obstacles for moving dislocations. Cross slip of $<a>$ dislocations on prismatic planes and climb of $<\mathrm{c}>$ dislocations are the main dynamic recovery mechanisms. The flat course of the stress-strain curves is a result of a dynamic balance between hardening and softening. To fulfill the von Mises criterion for compatible deformation of polycrystals, the nonbasal $<\mathrm{c}+\mathrm{a}>$ slip and /or deformation twinning are needed (Yoo et al., 2001). In coarse grained $\mathrm{Mg}$ and $\mathrm{Mg}$ alloys, twinning is observed in the early stages of plastic deformation.

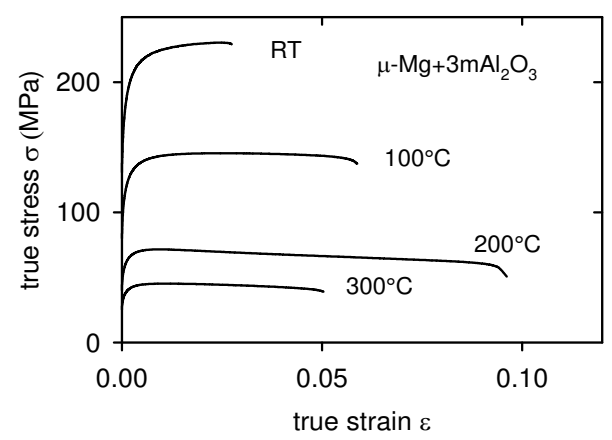

a)

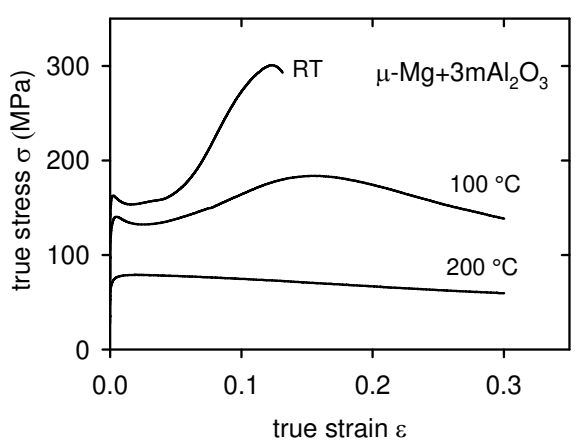

b)

Figure 17. True stress-true strain curves obtained for $\mu-\mathrm{Mg}+3 \% \mathrm{mAl}_{2} \mathrm{O}_{3}$ in tension (a) and compression (b). 


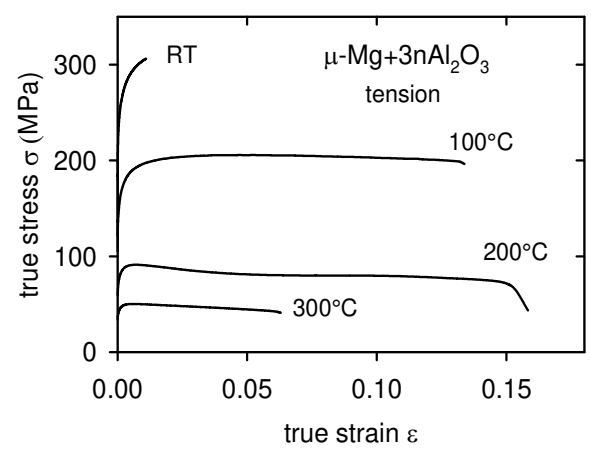

a)

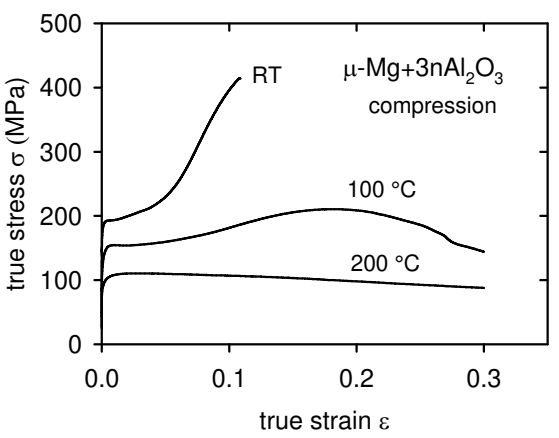

b)

Figure 18. True stress-true strain curves obtained for $\mu-\mathrm{Mg}+3 \% \mathrm{nAl}_{2} \mathrm{O}_{3}$ in tension (a) and compression (b).

The stress-strain curves obtained in tension are flat at temperatures above $100{ }^{\circ} \mathrm{C}$, there is a dynamic balance between hardening and softening. The work hardening rate is very close to zero. Tensile/compression yield stress asymmetry was studied by Mathis et al. using acoustic emission technique (Máthis et al., 2011). A broad maximum on the curves estimated at room temperature and at $100{ }^{\circ} \mathrm{C}$ was observed at a strain of about $10 \%$. Analysis of the acoustic emission signal revealed that during the compression tests below $200{ }^{\circ} \mathrm{C}$, the maximum of the twin formation is at a very beginning of the stress-strain curve. The twin boundaries are obstacles for dislocation motion. Therefore, twin growth caused an increase in the flow stress, which was manifested by a rapid decrease in the acoustic emission signal. In tension, a significant twin formation was observed during the entire test. Twinning mode of deformation requires formation of the new interface inside of grains. The energy of twin interfaces in $\mathrm{Mg}$ is relatively high (Koike et al., 2003). This leads to an increasing difficulty of twin nucleation with decreasing grain size. This has been confirmed by the acoustic emission measurements (Trojanová et al., 2008).

\begin{tabular}{|c|c|c|c|c|c|c|c|c|}
\hline \multirow{2}{*}{$\frac{\mathrm{T}}{{ }^{\circ} \mathrm{C}}$} & \multicolumn{4}{|c|}{ TYS (MPa) } & \multicolumn{4}{|c|}{ UTS (MPa) } \\
\hline & $\mu-\mathrm{Mg}$ & $\begin{array}{c}\mu \mathrm{Mg} \\
+3 \mathrm{mAl}_{2} \mathrm{O}_{3}\end{array}$ & $\begin{array}{c}\mu \mathrm{Mg} \\
+3 \mathrm{nAl}_{2} \mathrm{O}_{3}\end{array}$ & $\begin{array}{c}\mu \mathrm{Mg} \\
+3 \mathrm{nZrO}_{2}\end{array}$ & $\mu-\mathrm{Mg}$ & $\begin{array}{c}\mu \mathrm{Mg} \\
+3 \mathrm{mAl}_{2} \mathrm{O}_{3}\end{array}$ & $\begin{array}{c}\mu \mathrm{Mg} \\
+3 \mathrm{nAl}_{2} \mathrm{O}_{3}\end{array}$ & $\begin{array}{c}\mu \mathrm{Mg} \\
+3 \mathrm{nZrO}_{2}\end{array}$ \\
\hline 20 & 229.0 & 200.0 & 269.0 & 175.5 & 256.5 & 230.0 & 306.2 & 207.5 \\
\hline 100 & 145.7 & 128.2 & 172.6 & 114.8 & 161.2 & 145.4 & 205.5 & 125.8 \\
\hline 200 & 77.6 & 65.9 & 86.0 & 68.4 & 84.5 & 71.5 & 91.1 & 73.2 \\
\hline 300 & 48.5 & 41.5 & 48.5 & 46.2 & & 45.3 & 50.3 & 51.0 \\
\hline
\end{tabular}

Table 3. The tensile yield stress and ultimate tensile strength estimated at various temperatures in tension. 


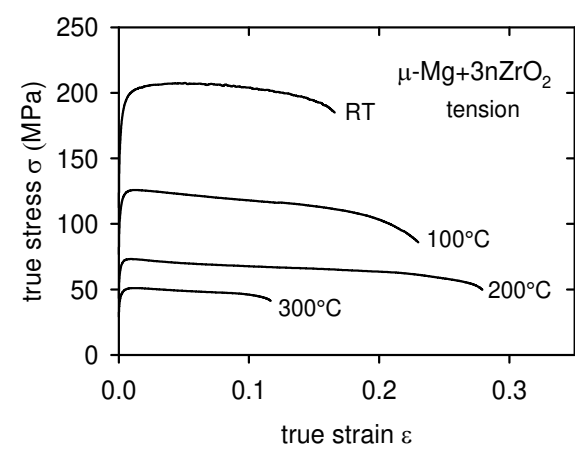

a)

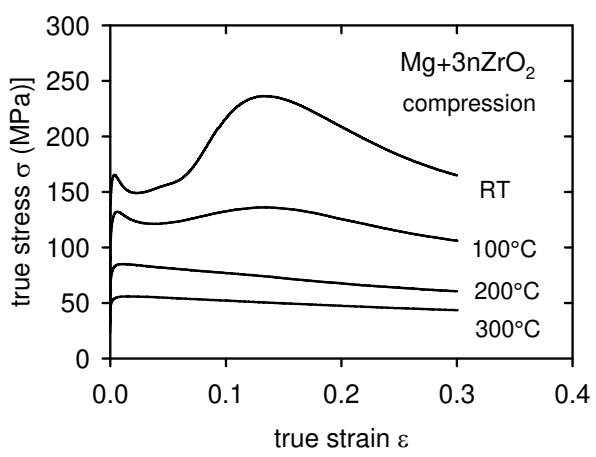

b)

Figure 19. True stress-true strain curves estimated at various temperatures for. $\mu-\mathrm{Mg}+3 \mathrm{nZrO} \mathrm{rample}_{2}$ in tension (a) and compression (b).

The temperature variations of the TYS and the UTS estimated for $\mu-\mathrm{Mg}$ and $\mu-\mathrm{Mg}$ with ceramic $\mathrm{mp}$ and $\mathrm{np}$ are introduced in Table 3. Relatively high values of the TYS and UTS were estimated. This is also influenced by small grain size of all materials as a result of the powder metallurgical preparation route. The Influence of the particles on the yield stress depends on the size of particles and kind of the np and, of course, on the test temperature. There are large differences in the values of the TYS at room temperature and $100{ }^{\circ} \mathrm{C}$. The difference in the values of the TYS for different composites measured at room temperature may be explained by the presence of the $\mathrm{np}$ and by the bonding between the particles and the matrix. The difference in the values of the TYS measured at $200{ }^{\circ} \mathrm{C}$ is small and at $300{ }^{\circ} \mathrm{C}$, the values of the yield stress are the same for $\mu-\mathrm{Mg}$ and $\mu-\mathrm{Mg}$ reinforced with $\mathrm{ZrO}_{2}$ and $\mathrm{Al}_{2} \mathrm{O}_{3}$ particles. Relatively high difference between the TYS and the UTS of $\mu-\mathrm{Mg}+3 \mathrm{Al}_{2} \mathrm{O}_{3}$ and $\mu-\mathrm{Mg}+3 \mathrm{ZrO}_{2}$ (approximately $100 \mathrm{MPa}$ ) may be caused by the strength of the bonding between $\mathrm{Mg}$ matrix and ceramic np. While this bonding between $\mathrm{Mg}$ and $\mathrm{Al}_{2} \mathrm{O}_{3} \mathrm{np}$ is nearly perfect, in the case of $\mathrm{ZrO}_{2}$ is weak as it will be demonstrated in the paragraph 4.1.

\begin{tabular}{|c|c|c|c|c|c|c|}
\hline $\mathbf{T}$ & & CYS (MPa) & & & JCS (MPa) & \\
\hline${ }^{\circ} \mathrm{C}$ & $\begin{array}{c}\mu \mathrm{Mg} \\
+3 \mathrm{mAl}_{2} \mathrm{O}_{3}\end{array}$ & $\begin{array}{c}\mu \mathrm{Mg} \\
+3 \mathrm{nAl}_{2} \mathrm{O}_{3}\end{array}$ & $\begin{array}{c}\mu \mathrm{Mg} \\
+3 \mathrm{nZrO}_{2}\end{array}$ & $\begin{array}{c}\mu \mathrm{Mg} \\
+3 \mathrm{mAl}_{2} \mathrm{O}_{3}\end{array}$ & $\begin{array}{c}\mu \mathrm{Mg} \\
+3 \mathrm{nAl}_{2} \mathrm{O}_{3}\end{array}$ & $\begin{array}{c}\mu \mathrm{Mg} \\
+3 \mathrm{nZrO}_{2}\end{array}$ \\
\hline 20 & 162.8 & 188.9 & 162,1 & 300.8 & 415.7 & 236.4 \\
\hline 100 & 135.2 & 140.8 & 124.7 & 183.7 & 210.6 & 136.2 \\
\hline 200 & 72.2 & 96.0 & 79.6 & 79.0 & 110.5 & 85.0 \\
\hline 300 & & & 52.2 & & & 56.9 \\
\hline
\end{tabular}

Table 4. The tensile yield stress and ultimate tensile strength estimated for various temperatures in compression. 
The temperature variations of the CYS and the UCS are introduced in Table 4 for Mg reinforced with various types of particles. It can be seen that while the values of the CYS of all materials studied are lower, the UCS values are higher than those measured in tension. The twinning mode of deformation in the early stages of deformation is easier in the compressive straining. New interfaces formed inside the grains are impenetrable obstacles for dislocation motion and they lead to hardening which is manifested with the local maximum on the stress-strain curve. The height of this maximum estimated at RT and $100{ }^{\circ} \mathrm{C}$ agree with the UCS value. The role of twinning decreases with increasing deformation temperature.

\subsubsection{Ultrafine grained magnesium}

Figure 20a shows the true stress-true strain curves for UFG-Mg deformed in compression at various temperatures. Samples were deformed either to fracture or at higher temperatures to predetermined strains. A pronounced upper yield point followed by the hardening stage was observed at temperatures between room temperature and $100{ }^{\circ} \mathrm{C}$. The stress-strain curves at temperatures higher than $150{ }^{\circ} \mathrm{C}$ have a steady state character. Stress-strain curves measured for UFG-Mg with 3 vol. \% of Gr np (UFG-Mg+3nGr) in compression are presented in Fig. $20 \mathrm{~b}$ for various temperatures. The local maximum at the beginning of the stress strain curve was in this case observed only at ambient temperature. The temperature dependences of the CYS and UCS estimated for both materials are shown in Table 5. Both stresses decrease rapidly with increasing temperature. The yielding phenomenon is very probably caused by the avalanche release of dislocations pinned at grain boundaries. It will be shown later in the paragraph 4.2 that the amplitude dependence of the logarithmic decrement in UFG-Mg indicates this phenomenon. Acoustic emission measurements detected no signal from the deformed sample at room temperature. This indicates that no dislocation pile-ups have been formed. In order to produce a pile-up of dislocations the grains need to contain a Frank-Read source operating in a cyclic way.

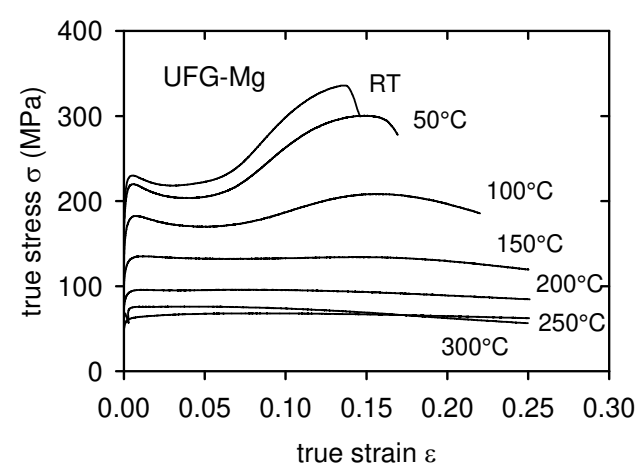

a)

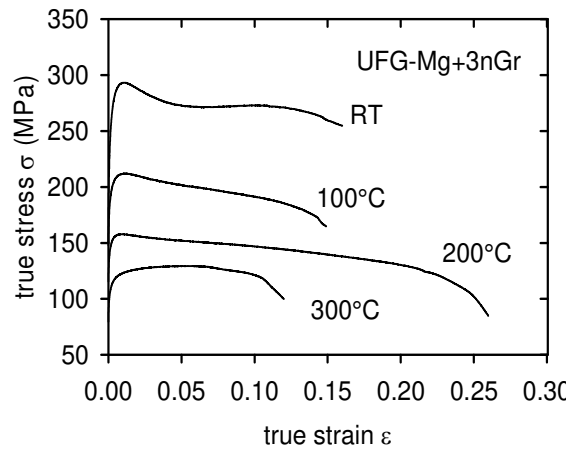

b)

Figure 20. True stress-true strain curves obtained for various temperatures in compression for UFG-Mg (a) and UFG$\mathrm{Mg}+3 \mathrm{nGr}(\mathrm{b})$. 


\begin{tabular}{ccccc}
\hline Temperature & \multicolumn{2}{c}{ UFG-Mg compression } & \multicolumn{2}{c}{ UFG-Mg+3Gr compression } \\
\hline $\mathbf{T}\left({ }^{\circ} \mathbf{C}\right)$ & CYS (MPa) & UCS (MPa) & CYS (MPa) & UCS (MPa) \\
\hline 22 & 222.0 & 335.9 & 259.4 & 293.2 \\
\hline 50 & 209.3 & 300.3 & & 212.0 \\
\hline 77 & & & 196.3 & \\
\hline 100 & 170.2 & 208.3 & & 157.9 \\
\hline 150 & 124.0 & 135.1 & 149.3 & 129.4 \\
\hline 200 & 89.5 & 95.7 & & \\
\hline 250 & 59.6 & 76.1 & & \\
\hline 300 & 59.6 & 68.0 & & \\
\hline
\end{tabular}

Table 5. The compressive yield stress and ultimate compression strength estimated for various temperatures for UFGMg and UFG_Mg with Gr np.

The maximum link length of a source to operate in a cyclic way becomes about D/2 ( $D$ is the separation of grain boundaries). The minimum resolved shear stress on the grain boundary due to the first loop can be written as

$$
\tau_{G B}=\frac{2 G b}{D}-\frac{G b}{D}=\frac{G b}{D}
$$

where $G$ is the shear modulus and $b$ the Burgers vector of dislocations. The first term is the operating stress of the source and the second is the back stress from the first loop that is forced up against the grain boundary. If $\tau_{\mathrm{GB}}$ exceeds the critical stress $\tau_{\mathrm{C}}$, required to an activation of an accommodating system, the first loop will escape in the grain boundary before the second loop is ejected from the source, and no pile-up will be formed (Nes et al., 2005). The stressstrain curves at temperatures higher than $150{ }^{\circ} \mathrm{C}$ exhibit a steady state character indicating a dynamic balance between hardening and softening.

It is clear that the Gr np increase the CYS. It is interesting to note that the UCS value of UFG$\mathrm{Mg}$ deformed at RT is higher than that of $\mathrm{Mg}+3 \mathrm{nGr}$. Values estimated at $300{ }^{\circ} \mathrm{C}$ for both materials show that the softening in the $\mathrm{Mg}+3 \mathrm{nGr}$ is lower than that in UFG-Mg. In the case where materials were prepared by milling, the refinement of the originally large grains into the UFG region is connected with large plastic deformation. This large plastic deformation is partially recovered during consolidation of the powder. Such mc and UFG materials usually contain a high density of dislocations in a heavy-deformation micro-structure (Mohamed, 2003). Np strengthening and grain refinement of the matrix are the key strengthening mechanisms in the UFG-Mg+3nGr nc (Lukáč et al., 2006, Estrin \& Vinogradov, 2013) A TEM micrograph of the UFG-Mg+3nGr sample deformed at RT is shown in Fig. 21. Dislocations pinned at grain boundaries are visible. The influence of grain size on the flow stress of magnesium alloys has been subject of a number of investigations (e.g. Mabuchi et al., 2001, 


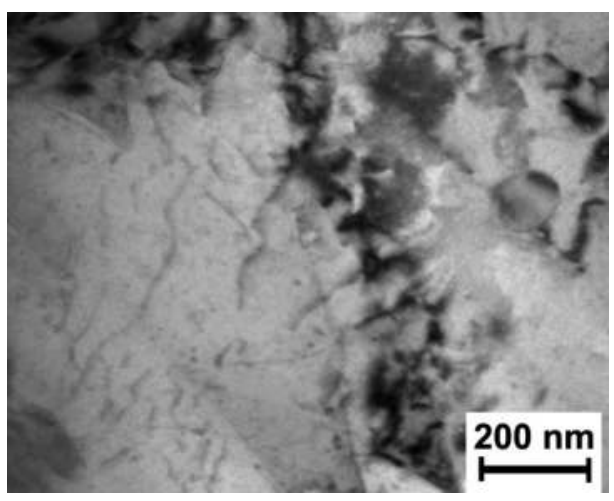

Figure 21. TEM of UFG-Mg+3nGr deformed at room temperature.

Anderson et al., 2003). Choi and co-workers (Choi et al., 2010) studied the deformation behaviour of ball milled $\mathrm{Mg}$ with the grain size from $60 \mathrm{~nm}$ up to $1 \mu \mathrm{m}$. They estimated that the YS is result of many mechanisms including the Hall-Petch strengthening, deformation twins, emission of partial dislocations and grain boundary sliding. Based on these estimations the deformation modes in the extruded $\mathrm{Mg}$ can be at RT divided into three regions:

(1) Mc region (the grain size above $1 \mu \mathrm{m}$ ): the yield stress of $\mathrm{Mg}$ follows the Hall-Petch relationship.

(2) UFG region (the grain size between $100 \mathrm{~nm}$ and $1 \mu \mathrm{m}$ ): the YS of Mg negatively deviates from the Hall-Petch relationship.

(3) Nc region (the grain size smaller than $100 \mathrm{~nm}$ ): the slope of the yield stress dependence on the grain size is negative.

While for $\mathrm{mc} \mathrm{Mg}$ the interaction of dislocations with grain boundaries and/or twin boundaries can be considered as significantly affecting plastic deformation, for UFG-Mg the dislocation pile-up mechanism loses its significance; twining and grain boundary sliding gradually contributes to plastic deformation.

\subsubsection{X-ray analysis}

Deformed UFG-Mg samples were investigated by the high resolution X-ray diffraction peak profile analysis. The diffraction profiles are evaluated by assuming that peak broadening is caused by small crystallites and strain caused by dislocations. The Williamson-Hall plots (integral breadth $\beta$ vs. $\sin \vartheta$, where $\vartheta$ is the Bragg angle) were constructed. The measured physical profiles are fitted by theoretical profiles calculated on the basis of well-established profile functions of size and strain. Both strain and strain anisotropy are accounted for by the dislocation model of lattice distortions (Wilkens, 1970; Ungár \& Borbely, 1996). In a crystal containing dislocations, the mean square strain is done by Wilkens (1970) 


$$
\left\langle\varepsilon_{g, L}^{2}\right\rangle \cong\left(\rho C b^{2} / 4 \pi\right) f(\eta)
$$

where $\mathrm{Q}$ is the density of dislocations and $\mathrm{b}$ is their Burgers vector, $\mathrm{C}$ is the dislocation contrast factor, $f(\eta)$ is the Wilkens function, where $\eta=L / R_{e}\left(R_{e}\right.$ is the effective outer cut-off radius of dislocations), $\mathrm{L}$ is the Fourier length defined as $\mathrm{L}=\mathrm{na}_{3}\left(\mathrm{a}_{3}=\lambda / 2\left(\sin \vartheta_{2}-\sin \vartheta_{1}\right)\right), \mathrm{n}$ are integers starting from zero, $\lambda$ is the wavelength of X-rays and $\left(\vartheta_{2}-\vartheta_{1}\right)$ is the angular range of the measured diffraction profile. In the case of hexagonal polycrystals, where dislocations with various Burgers vectors take place in deformation, the average contrast factor may be obtained by the weighted linear combination of the individual contrast factors for the active sub slip systems:

$$
\left\langle C b^{2}\right\rangle=\sum_{i=1}^{N} f_{i}\left\langle C^{i}\right\rangle b_{i}^{2}
$$

where $\mathrm{N}$ is the number of the different activated sub slip systems, $\left\langle C^{i}\right\rangle$ is the average dislocation contrast factor corresponding to the ith sub slip system and $\mathrm{f}_{\mathrm{i}}$ are the fractions of the particular sub slip systems by which they contribute to the broadening of a specific reflection. The average contrast factors for a single sub slip system (hk.l) in hexagonal crystals are (Dragomir \& Ungár, 2002):

$$
\left\langle C_{h k !}\right\rangle=\left\langle C_{h k .0}\right\rangle\left[1+q_{1} x+q_{2} x^{2}\right]
$$

where $x=(2 / 3)(\ell / g a)^{2}, q_{1}$ and $q_{2}$ are parameters depending on the elastic properties of the material, $\mathrm{C}_{\mathrm{hk} .0}$ is the average contrast factor corresponding to the hk. 0 type reflections, $g$ is the absolute value of the diffraction vector and $a$ is the lattice constant in the basal plane. The $\mathrm{q}_{1}$ and $\mathrm{q}_{2}$ parameters and the values of $\mathrm{C}_{\mathrm{hk} .0}$ have been calculated for hexagonal crystals and compounds in (Dragomir \& Ungár, 2002). Two Burgers vectors types were taken into account: $\langle a\rangle=\frac{1}{3}\langle\overline{2} 110\rangle$ and $\langle c+a\rangle=\frac{1}{3}\langle\overline{2} 113\rangle$. Using the scheme described by Kužel \& Klimanek (1989), it is possible to take for the number $\mathrm{N}$ of sub-slip systems in eq. (12) with the $<\mathrm{a}>$ or $<\mathrm{c}+\mathrm{a}>\mathrm{Burger}$ vector $\mathrm{N}\langle a\rangle=4$ and $\mathrm{N}\langle c+a\rangle=5$, respectively. Once the Burgers vector types are determined, the value of $\left\langle C_{h k .0} b^{2}\right\rangle$ and the dislocations density @ can also be calculated; for further details see (Kužel \& Klimanek, 1989). The experimental values of $\mathrm{q}_{1}$ and $\mathrm{q}_{2}$ denoted as can be estimated by the whole profile fitting procedure (details see (Kužel, 1998)).

The Williamson-Hall plots in terms of the integral breadth $\beta$ vs. the magnitude of the reciprocal lattice vector $G$ ( $G$ represents $\sin \vartheta$ ) are shown in Figs. 22 for samples deformed at various temperatures. Circles correspond to the values calculated from the experimental data (Kužel, 1998). Squares correspond to the values calculated on the basis of the model (Dragomir \& Ungár, 2002). The fitting procedure allows to estimate the density of basal $<a>$ dislocations, the 


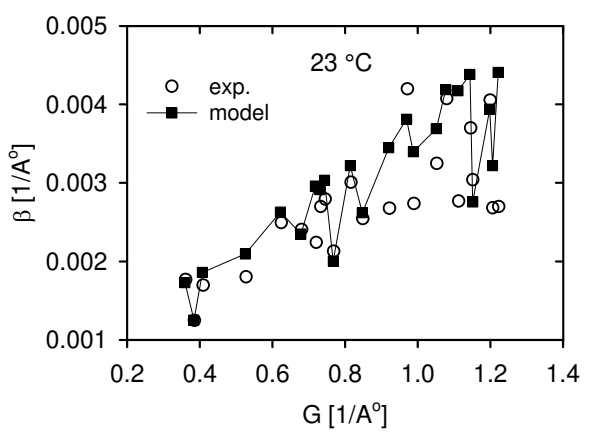

a)

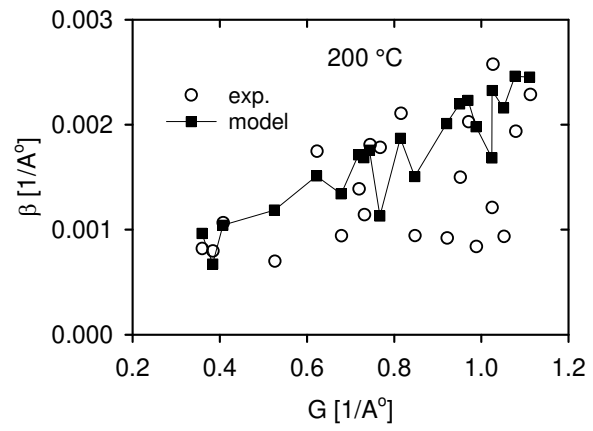

c)

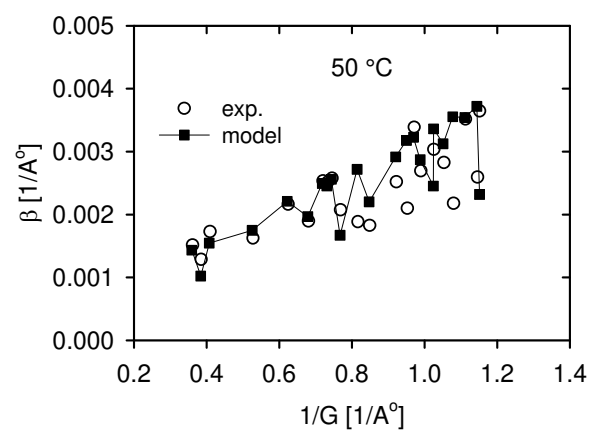

b)

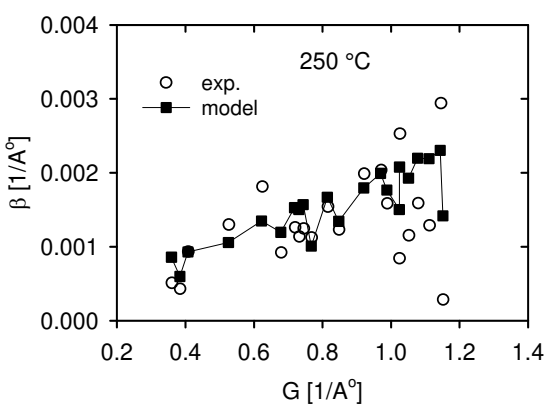

d)

Figure 22. The integral breadths for the sample deformed at RT (a), $50^{\circ} \mathrm{C}$ (b), $200^{\circ} \mathrm{C}$ (c), $250^{\circ} \mathrm{C}$.

density of $\langle\mathrm{C}+\mathrm{a}\rangle$ dislocations and the grain size depending on the testing temperature. The results are given in Table 6. From Table 6 it follows that the basal dislocation density decreases with increasing deformation temperature, while the fraction of $\langle\mathrm{c}+\mathrm{a}>$ dislocations is constant. The grain size growth has been also observed with increasing deformation temperature. Máthis et al., (2004) used the similar method to study the evolution of the dislocation density with the Burgers vector of different types as a function of the testing temperature in a coarse grained $\mathrm{Mg}$. They found that at room temperature and at $100{ }^{\circ} \mathrm{C}$, the dominant dislocations are $<\mathrm{a}>$ or mainly basal dislocations.

\begin{tabular}{lllll}
\hline Deformation temperature $\left({ }^{\circ} \mathrm{C}\right)$ & 23 & 50 & 200 & 250 \\
\hline Density of basal dislocations $\rho_{\text {<a> }} 10^{14}\left(\mathrm{~m}^{-2}\right)$ & 4.04 & 3.0 & 1.5 & 1.2 \\
\hline$\rho_{<\mathrm{c}+\mathrm{a}} / \rho_{\text {<a> }}$ & 0.1 & 0.1 & 0.1 & 0.1 \\
\hline Grain size $(\mathrm{nm})$ & 150 & 200 & 350 & 400 \\
\hline
\end{tabular}

Table 6. Basal dislocation density $\rho_{<a>}$, density of $<c+a>$ dislocations $\rho_{<c+a>}$ and grain size estimated for various deformation temperatures. 
At higher temperatures, the fraction of $<a>$ dislocations decreases, whereas the fraction of $<\mathrm{c}$ $+\mathrm{a}>$ dislocations increases. The fraction of $<\mathrm{c}>$ dislocations remains practically unchanged. The average total dislocation density increased considerably with strain as compared to the value in the as-cast state.

However, with increasing deformation temperature, the increment of the dislocation density decreased strongly in the plastically deformed sample. The concomitant increase of the fraction of $\langle\mathrm{c}+\mathrm{a}\rangle$ dislocations and the decrease of the average dislocation density with increasing deformation temperature can be explained by the dynamic recovery mechanism/-s. The results obtained in our study for UFG-Mg exhibit similar decrease in the basal dislocation density. The fraction of the $<\mathrm{c}+\mathrm{a}>$ dislocations in UFG Mg remains constant, while it increases in the coarse grained material. This is very probably caused by the different deformation mechanisms in the UFG-material.

\section{Internal friction measurements}

\subsection{Amplitude dependence of internal friction}

The damping measurements were carried out in a vacuum (about $30 \mathrm{~Pa}$ ) at room temperature. The specimens fixed at one end were excited into resonance by a permanent magnet fixed at the free side of the bending beam and a sinusoidal alternating magnetic field. The internal friction was characterised by the logarithmic decrement $\delta$ of the free decay of the vibrating beam $\delta=\ln \left(A_{n} / A_{n+1}\right)$, where $A_{n}$ and $A_{n+1}$ are the amplitudes of a free decay of vibrations after $\mathrm{n}$ and $(\mathrm{n}+1)$ cycles, respectively. The resonance frequency ranged from 130 to $160 \mathrm{~Hz}$. The strain amplitude dependences of the logarithmic decrement were measured. The specimens were annealed step by step at increasing temperatures up to $500^{\circ} \mathrm{C}$ for $0.5 \mathrm{~h}$ and after each annealing cycle quenched into water of room temperature. The annealing at higher temperatures was performed in an argon atmosphere to avoid oxidation. The damping measurements were carried out immediately after heat treatment and quenching at room temperature.

Figure 23 shows the logarithmic decrement plotted against the logarithm of the maximum strain amplitude for $\mu-\mathrm{Mg}+3 \mathrm{nZrO}_{2}$ samples. The logarithmic decrement was measured before (as received - as rec) and after step by step annealing at increasing upper temperature of the cycle. It can be seen that the measured strain dependence of the logarithmic decrement exhibits two regions and can be expressed as

$$
\delta(\varepsilon)=\delta_{0}+\delta_{H}(\varepsilon)
$$

where $\delta_{0}$ is the amplitude independent component (or only weakly dependent on the maximum strain amplitude) found in the first region, for lower strain amplitudes. In the second region, for higher strain amplitudes, the component $\delta_{\mathrm{H}}(\varepsilon)$ depends on the strain amplitude (amplitude dependent internal friction - ADIF); it increases with increasing strain amplitude. The upper temperature of the thermal cycling influences the logarithmic decrement. In the case of the $\mu-\mathrm{Mg}+3 \mathrm{nZrO}_{2}$ composite, the thermal treatment influences mainly the amplitude independent component of the decrement. It is important to note that very high values of 
damping in the amplitude independent component - in order of $10^{-2}$ - were obtained. The strain amplitude dependences of the logarithmic decrement for $\mu-\mathrm{Mg}+3 n \mathrm{Al}_{2} \mathrm{O}_{3}$ are given in Figures 24. Figure 24a shows the strain amplitude dependence of the logarithmic decrement for specimens annealed up to $300^{\circ} \mathrm{C}$. Figure $24 \mathrm{~b}$ shows the strain amplitude dependence of the logarithmic decrement for specimens annealed at temperatures between 300 and $500{ }^{\circ} \mathrm{C}$. The thermal cycling influences mainly the amplitude dependent component $\delta_{\mathrm{H}}$ that increases with increasing upper temperature of the cycle, if the upper temperature is between room temperature and $300{ }^{\circ} \mathrm{C}$. For the upper temperature between 300 and $500{ }^{\circ} \mathrm{C}$, the $\delta_{\mathrm{H}}$ component decreases with increasing upper temperature.

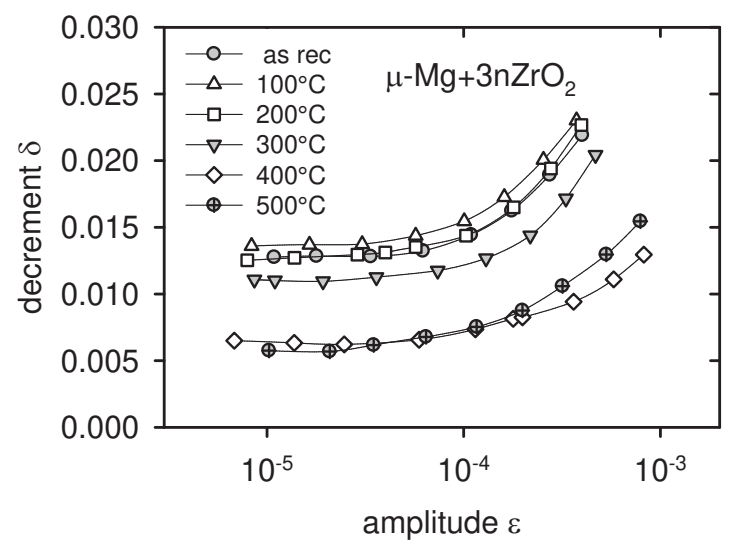

Figure 23. Amplitude dependence of decrement measured after annealing at increasing temperatures.

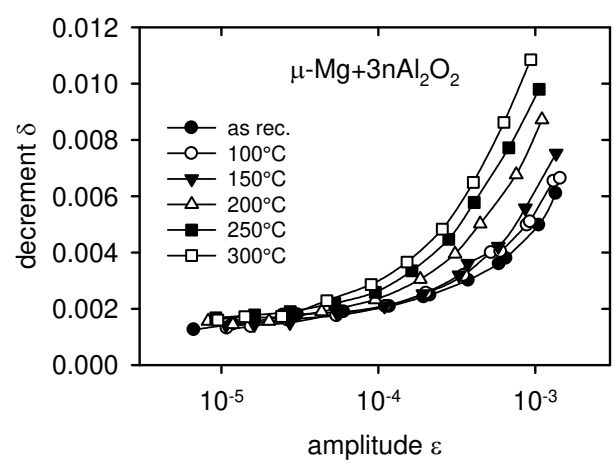

a)

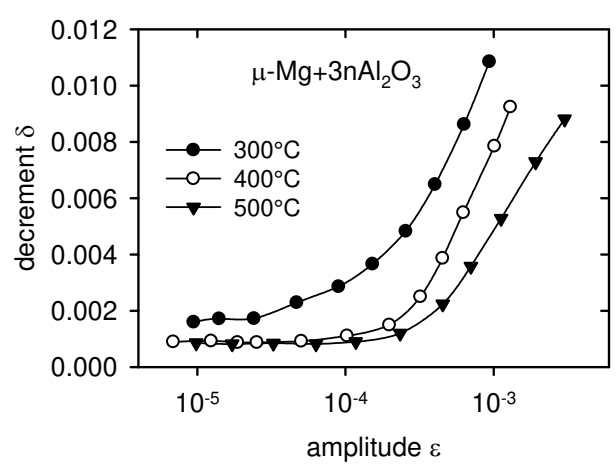

b)

Figure 24. Amplitude dependence of the decrement for $\mu-\mathrm{Mg}+3 n \mathrm{nl}_{2} \mathrm{O}_{3}$ annealed at temperatures up to $300^{\circ} \mathrm{C}(\mathrm{a})$ and temperatures between 300 and $500{ }^{\circ} \mathrm{C}$ (b). 
The strain amplitude dependences of the logarithmic decrement measured in UFG-Mg after thermal cycling are given in Figure 25a. Only a slight influence of thermal cycling on the $\delta$ versus $\varepsilon$ curves can be observed. Figure $25 \mathrm{~b}$ shows the plots of $\delta$ versus $\varepsilon$ for UFG-Mg+3nGr. It can be seen that the thermal cycling causes a slight decrease of the logarithmic decrement at small strain amplitudes. The $\delta_{\mathrm{H}}$ component changes only very slightly with increasing temperature of the cycle. Figure 26 shows the strain amplitude dependence of the logarithmic decrement for various materials before annealing (as received). The value of the critical strain $\varepsilon_{\mathrm{c}}$ at which the logarithmic decrement begins to increase with strain amplitude depends on annealing temperature and it depends on the kind of particles.

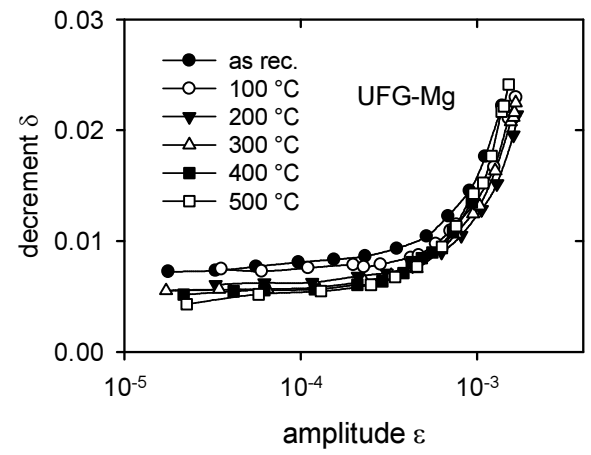

a)

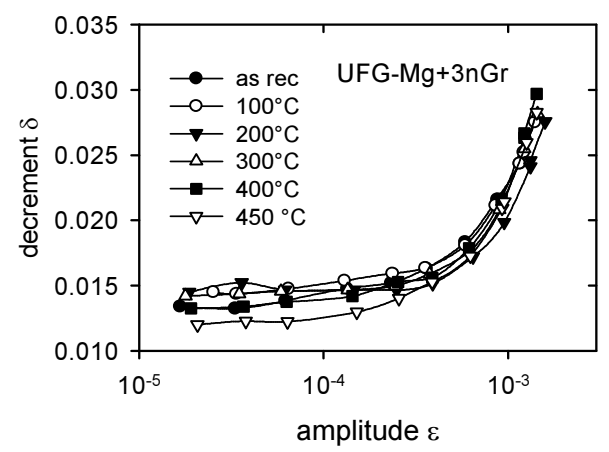

b)

Figure 25. Strain amplitude dependence of the decrement for UFG-Mg (a) and UFG-Mg+3nGr (b), annealed at increasing temperature.

It is generally accepted that the $\delta_{0}$ component is connected with the material microstructure and the amplitude dependent component $\delta_{\mathrm{H}}$ is due to an interaction of dislocations with point defects (e.g. solute atoms). The dislocations contribute to the damping capacity by the motion of vibrating dislocation lines. Particulates $\left(\mathrm{Al}_{2} \mathrm{O}_{3}, \mathrm{ZrO}_{2}, \mathrm{Gr}\right)$, as secondary phases, may improve the damping capacity of alloys. The particles in a composite may cause an increase in the dislocation density as a result of thermal strain mismatch between the ceramic particles and the matrix during preparation and/or thermal treatment. The difference between the coefficients of thermal expansion (CTE) of the particles and the matrix may create the thermal residual stresses after cooling from the processing temperature to room temperature. The thermal stresses are also generated during heat treatment and when composites are heated and cooled through a temperature range (thermal cycling). In generally, there are biaxial or triaxial stress fields located near the reinforcement-matrix interface. The amplitudes of the stress field decrease with increasing distance from the interface. In a simple one-dimensional model, the thermal stresses $\sigma_{\mathrm{TS}}$, produced by a temperature change $\Delta \mathrm{T}$, at the interface are given by (Chawla, 1991) 


$$
\sigma_{T S}=\frac{E_{F} E_{M}}{\left(E_{F} f+E_{M}(1-f)\right)} f \Delta \alpha \Delta T
$$

where $\Delta \alpha$ is the mismatch of the CTE values between the reinforcements and the matrix, $E_{\mathrm{F}}$ and $E_{\mathrm{M}}$ are the values of the Young's modulus for the reinforcement and the matrix, respectively and $\mathrm{f}$ is the volume fraction of the reinforcement. The CTE of the matrix is much higher than that of the reinforcement. Thus after cooling, the tensile thermal residual stresses are created in the matrix. The thermal stresses may relax around the matrix-reinforcement interface by emitting dislocation. An increase in the dislocation density near reinforcement has been calculated as (Arsenault \& Shi, 1986, Dunand \& Mortensen, 1991):

$$
\Delta \rho=\frac{B f \Delta \alpha \Delta T}{b(1-f)} \frac{1}{t}
$$

where $t$ is the minimum dimension of reinforcement, $b$ is the magnitude of the Burgers vector of dislocations and $B$ is a geometrical constant (depending on the aspect ratio). The newly formed dislocations may be sources of the higher damping capacity because of the motion of vibrating dislocation lines under cycling loading. According to the Granato-Lücke theory (Granato, \& Lücke, 1981), weak and strong pinning points restrict motion of dislocations in their glide plane. At low strain amplitudes (stresses), dislocation bows out between the weak pinning points, leading to the amplitude independent logarithmic decrement. The dislocation remains anchored at the strong pinning points. At higher strain amplitudes, the force exerted on the weak pinning points becomes higher than the binding force of the weak pinning points. The dislocation segments break away from some weak pinning points within longer dislocation segments. This leads to a drastic instantaneous increase in the dislocation strain and thus giving rise to the level of the logarithmic decrement. The amplitude dependent component of the decrement depends on the dislocation density, length of shorter and longer dislocation segments. At temperatures higher than $0 \mathrm{~K}$, the breakaway of shorter dislocation segments is thermally activated. During thermal cycling, new dislocations are created due to the difference in the CTEs (see Eq. (10)). An increase in the dislocation density, while the number of weak pinning points remains constant, increases effectively the length of dislocation segment between weak pinning points and hence the $\delta_{\mathrm{H}}$ component should increase, which is observed. The higher temperature of the cycling, the higher the dislocation density and the higher increase in the effective length of the shorter dislocation segments. The critical strain $\varepsilon_{\mathrm{c}}$ at which the decrement becomes to be amplitude dependent is determined by the interaction energy between dislocations and the weak pinning points and the distance between the pinning points. As the distance between weak pinning point increases with the upper temperature, the dislocations can break away from the weak pinning point under lower critical stress and thus, the value of $\varepsilon_{\mathrm{c}}$ should decrease with increasing upper temperature, which is observed. The values of $\varepsilon_{\mathrm{c}}$ for a composite are proportional to the yield stress of the composite matrix. It should be consider that the value of $\varepsilon_{\mathrm{c}}$ can be influenced by the thermal stresses due to the 
difference in CTEs for both components of the composite. In mc and UFG Mg no new dislocations are created during thermal cycling. Hence, it is expected only a slight influence of the thermal cycling on the $\delta$ versus $\varepsilon$ curves, which is in agreement with experimental results.

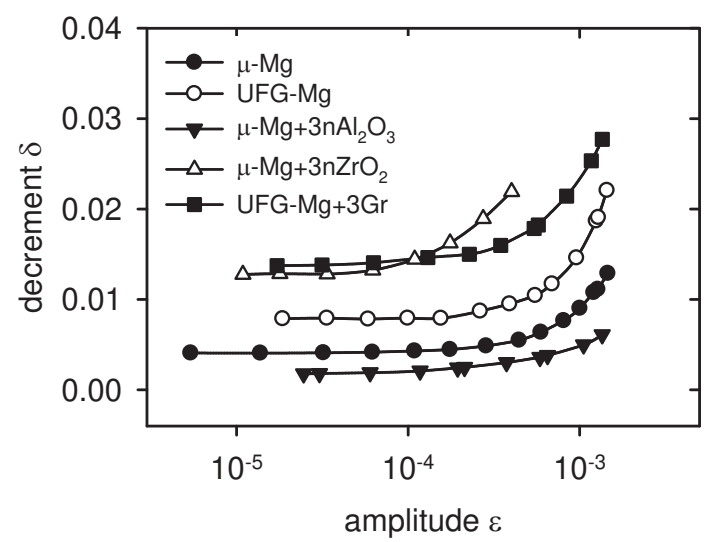

Figure 26. Amplitude dependence of the decrement for $\mu-M g$, UFG-Mg and $\mu-M g$ and UFG-Mg reinforced with $\mathrm{np}$.

Interfaces may contribute to the damping behaviour of composite materials. Due to a large difference in the coefficients of thermal expansion between the particles and the matrix, high thermal residual stresses are created around the particles. The thermal stresses with temperature can relax and plastic zones of tangled dislocation are formed. Their average radius depends on the difference in CTEs, particles radius and the change of temperature. The higher the matrix yield stress, the smaller radius of the plastic zones (Dunand \& Mortensen, 1991). Plastic zones may also contribute to the damping behaviour.

The contribution of interfaces to internal friction depends on the character of interfacial bonding. The interface damping should be considered. The internal friction of a composite with the perfectly bonded interface (interface is incoherent) depends on the shape of particles, their volume fraction and the magnitude of local stress at the particle-matrix interface. Assuming that all the particles have the same diameter, the logarithmic decrement is given as (Zhang et al., 1994a)

$$
\delta=\frac{4.5(1-v)}{\pi(2-v)} V_{p}
$$

where $V_{\mathrm{p}}$ is the volume fraction of particles and $v$ is the Poisson ratio of the matrix. The effect of the perfectly bonded interfaces on the damping behaviour becomes more significant at high temperatures; in $\mathrm{Mg}$ based composites this could be above $150{ }^{\circ} \mathrm{C}$. The matrix becomes 
relatively soft relative to the nanoparticles. Hence, the internal friction at the interface may be thermally activated.

In the case of weak bonding at the interface, interfacial slip (sliding at the interface) may occur. In this case, the frictional energy loss caused by the sliding at interfaces may become a primary source of damping. The damping component due to interfacial slip under the applied stress amplitude $\sigma_{0}$ can be expressed as (Zhang et al., 1994a)

$$
\delta=\frac{3 \pi^{2}}{2} \frac{\kappa \sigma_{r}\left(\varepsilon_{0}-\varepsilon_{c r}\right)}{\sigma_{0}^{2} / E_{C}} V_{p}
$$

where $\kappa$ is the friction coefficient between both components of the composite, $\sigma_{\mathrm{r}}$ is the radial stress at the particle-matrix interface corresponding to the stress amplitude $\sigma_{0}, \varepsilon_{0}$ is the strain amplitude corresponding to $\sigma_{0}$. The critical interface strain $\varepsilon_{\mathrm{cr}}$ corresponding to the critical interface shear stress $\tau_{\mathrm{cr}}$ is the strain at which the sliding on the on interface begins. $E_{\mathrm{C}}$ is the elastic modulus of the composite. For weakly bonded interfaces, the critical strain $\varepsilon_{\mathrm{cr}}$ is assumed to be much lower than the strain amplitude $\varepsilon_{0}$ and then

$$
\delta=\frac{3 \pi^{2}}{2} \frac{\kappa \sigma_{r}}{\sigma_{0}} V_{p} .
$$

The stress concentration factor $\sigma_{\mathrm{r}} / \sigma_{0}$ has been reported to be 1.1-1.3 (Zhang et al., 1994b). The model does not take into account possible effects of temperature or frequency on damping and therefore the predictions of the model may be taken only as the first approximation. Very high values of $\delta_{0}$ for mc and nc $\mathrm{Mg}$ reinforced by zirconia $\mathrm{np}$ and Gr np are very probably caused by interfacial slip due to weak bonding between particles and matrix. The effect of an additional damping due to the influence of particle can be clearly seen in Figure 26. Therefore, the effect of an additional damping due to the influence of particles may be estimated. The measured increase in $\delta_{0}$ due to the addition of $\mathrm{ZrO}_{2} \mathrm{np}$ to $\mu-\mathrm{Mg}$ and $\mathrm{Gr} n \mathrm{n}$ to UFG-Mg is about $0.008-0.009$ (Figure 26). Taking for the friction coefficient a typical value of $\sim 0.08$, the relation (10) predicts a value for an additional damping owing to interfaces of $\delta_{0 \mathrm{i}}=0.04$. The discrepancy between the predicted and measured value may be caused by a non-uniform strain state in specimens because they were subjected to bending in experiment. Hence, the stress (strain) level can reach its critical value at which the interface sliding starts only in some region of the measured specimen. Accordingly, the measured interface-damping component is lower than the predicted value. High values of the decrement component $\delta_{0}$ obtained for mc and UFG$\mathrm{Mg}$ are very probably caused by grain boundary sliding support by diffusion processes. On the other hand, the observed decrease in the amplitude independent component of $\mu-\mathrm{Mg}$ $+3 \mathrm{nAl}_{2} \mathrm{O}_{3}$ comparing with $\mu-\mathrm{Mg}$ may be explained according to the following way: $\mathrm{Np}$ situated in grain boundaries prevent the grain boundary sliding which contribute significantly to the amplitude independent component of decrement. 


\subsection{Temperature relaxation spectrum of internal friction}

The temperature dependent internal friction (TDIF), internal friction spectrum, is the temperature or frequency dependence of damping. Internal friction spectra were measured in a DMA 2980 (TA Instruments) apparatus in a single heating and cooling process. Measurements were performed at various frequencies from $0.1 \mathrm{up}$ to $2 \mathrm{~Hz}$. Throughout the measurements the strain amplitude was $1.2 \times 10^{-4}$. The heating as well as cooling rate was $1 \mathrm{~K} / \mathrm{min}$.

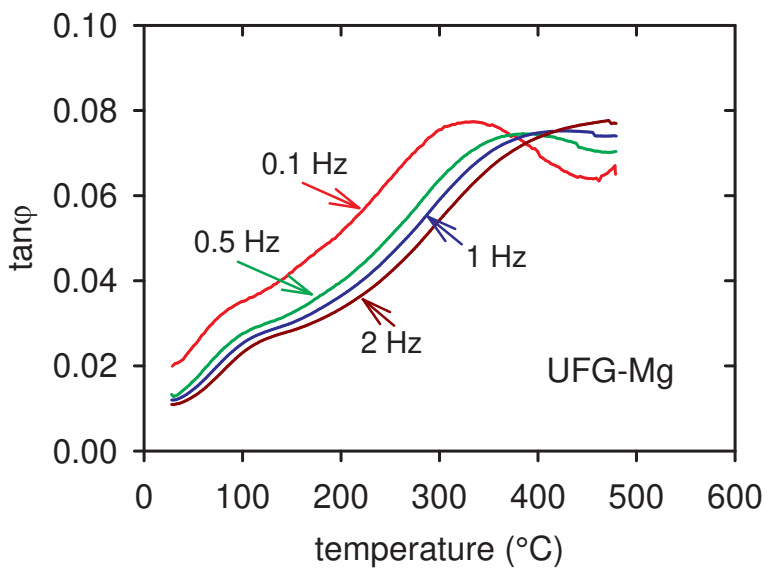

Figure 27. Temperature relaxation spectrum of IF estimated for various frequencies.

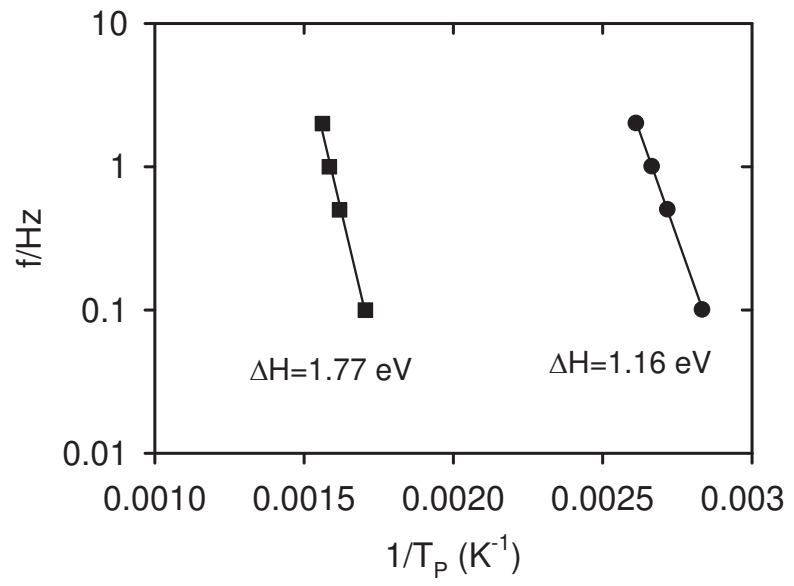

Figure 28. Arrhenius plots estimated for both peaks. 
The internal friction in a material is a result of internal processes, which occurs during alternating stress cycles imposed on it and these processes originate from the interactions among structural components in the material. The presence of point, line, and planar defects within a stressed material often causes the internal friction to occur because of the atomic movement, rearrangement, or realignment of the defects under the application of a stress. These techniques can be used to characterize types of structure defects.

Figure 27 shows the temperature dependence of the internal friction IF=tan $\varphi$ (Nowick \& Berry. 1972) measured at $0.1 \mathrm{~Hz}$ during heating (heating rate $1 \mathrm{~K} / \mathrm{min}$.). Two peaks showing different intensities have been found: the weak low temperature peak (P1) and the more intense high temperature peak (P2). It can be seen that both peaks shift to a higher temperatures with increasing frequency, indicating that they may be relaxations peaks.

\begin{tabular}{ccc}
\hline $\mathbf{f ( H z )}$ & $\mathbf{P 1}\left({ }^{\circ} \mathrm{C}\right)$ & $\mathbf{P 2}\left({ }^{\circ} \mathrm{C}\right)$ \\
\hline 0.1 & 79.6 & 313.2 \\
\hline 0.5 & 94.7 & 344.5 \\
\hline 1 & 103.3 & 357.9 \\
\hline 2 & 109.5 & 367.2 \\
\hline
\end{tabular}

Table 7. Temperatures of the relaxation peaks estimated for various frequencies.

The curves introduced in Fig. 27 were measured during one heating course in the multifrequent mode. The internal friction peaks are assumed to be imposed by a background $\mathrm{IF}_{\mathrm{b}}$ expressed by

$$
\mathrm{IF}_{\mathrm{b}}=\mathrm{A}+\mathrm{B} \exp \left(-\mathrm{C}_{\mathrm{b}} / \mathrm{kT}\right)
$$

where $\mathrm{k}$ is the Boltzmann constant, $\mathrm{T}$ is the absolute temperature, $\mathrm{A}, \mathrm{B}$, and $\mathrm{C}_{\mathrm{b}}$ are constants. After subtracting the background by using a fitting program PeakFit, the peak temperature $T_{P}$ was estimated for the both relaxation peaks. The temperatures of both peaks estimated for various frequencies are given in Table 7 . The peak widths are broader than that for a Debye peak, characterised by a single relaxation time. The internal friction peak appears at the condition $\omega \tau=1$ (Nowick \& Berry. 1972), with

$$
\omega t=\omega t_{0} \exp (D H / \mathrm{k} T)
$$

where $\omega$ is the angular frequency $(=2 \pi \mathrm{f}$, $\mathrm{f}$ is the measuring frequency), $\tau$ is the mean relaxation time, $\tau_{0}$ is the pre-exponential factor, and $\Delta H$ is the mean activation enthalpy. 


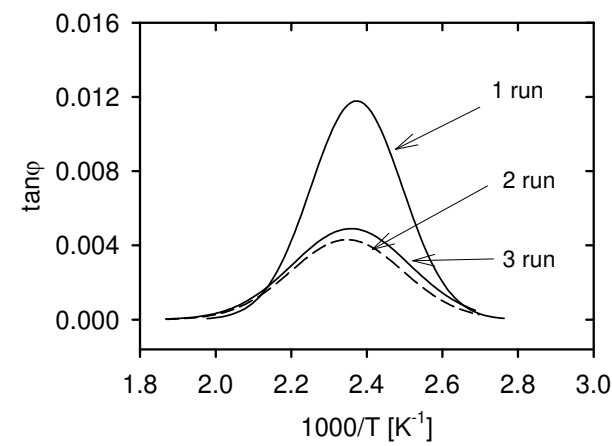

a)

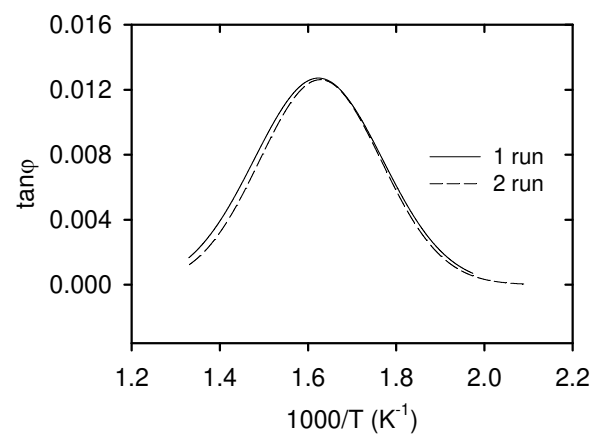

b)

Figure 29. Background subtracted low (a) and high (b) temperature peaks after a prestraining of $2.55 \%$.

\subsubsection{Low temperature peak}

Figure 28 shows the semilogarithmic plot of the frequency versus reciprocal value of peaks temperatures $T_{P}$ (estimated for both peaks) so called Arrhenius plots. From the slope and intercept of the straight line, the mean activation enthalpy for the low temperature peak $\Delta \mathrm{H}$ has been obtained and its value is $1.16 \pm 0.05 \mathrm{eV}$.

As far as the low temperature peak may have a dislocation nature, prestraining of the sample at low temperature should influence the height of the peak. Therefore, the samples were deformed by rolling. Deformation by rolling at room temperature $(\varepsilon \approx 2.55 \%)$ increases the strength of the low temperature peak, as it is obvious from Figure 29a (the peak was extracted from the internal friction spectrum subtracting the background damping). However, the peak is stronger only in the first run after prestraining. In the second and third run, the height of the peak is approximately the same as in the as-prepared state, and the height is lower than in the first run.

The strain amplitude dependent component of the logarithmic decrement (Figure 25a) indicates free dislocation loops in the material. IF peaks estimated in the second and third heating and cooling runs are practically the same. Beside this original dislocation population, the prestraining of the sample produced new dislocations which were practically completely recovered during the heating course of measurements. Owing to small grain size the grain boundaries were very probably the sources as well as sinks of the newly created dislocations. As mentioned above, the dominant deformation mode in magnesium is the basal slip; glide of $<\mathrm{a}>$ dislocations. The secondary conservative slip may be realised by motion of $<\mathrm{a}>$ dislocations on prismatic and pyramidal planes of the first kind. Couret \& Caillard (1984a,b) studied by TEM prismatic glide in magnesium over a wide temperature range. They have reported that the screw dislocations with the Burgers vector of $1 / 3[1120]$ are able to glide on prismatic planes and their mobility is much lower than the mobility of edge dislocations. The deformation is controlled by the thermally activated glide of those screw dislocation segments. A single controlling mechanism has been identified as the Friedel-Escaig mechanism. This mechanism assumes a dissociated dislocation on a compact plane (0001) that joints together along a critical length $L_{\mathrm{r}}$ producing double kinks on non-compact plane. Dislocations in very small grains are 
pinned at the grain boundaries and this is the reason why this dislocation population is so stable. On the other hand, the newly created dislocations during cold rolling are only slightly pinned and they are recoverable during heating part of the measurement cycle.

\subsubsection{High temperature peak}

The high temperature peak was observed at a temperature of $\approx 345{ }^{\circ} \mathrm{C}(0.5 \mathrm{~Hz})$. The cold prestraining of the sample did not affect the strength of the high temperature peak, as it can be seen from Fig. 29b. Position and height of the peak are very stable during heating as well as cooling. The activation energy was obtained from the frequency dependence of the peak temperature (Arrhenius plot) to be $1.77 \pm 0.05 \mathrm{eV}$ (see Figure 28).

The presence of the high temperature peak in magnesium has been reported by Kê (Kê, 1947). He described this peak as being related to the grain boundary relaxation.

Grain boundaries in materials with the small grain size contain a dense network of overlapping grain boundary dislocations. Grain boundary sliding is realized by the slip and climb (providing a maintenance of vacancy sources and sinks) of the grain boundary dislocations. Since both modes of the grain boundary dislocation motion must occur simultaneously, the slower one will control the grain boundary sliding. The climb mode involves jog formation and grain boundary diffusion and both modes of the grain boundary dislocation movement may be affected by the interaction of the grain boundary dislocations with impurities segregated in grain boundaries. According to Lakki et al. (1998) the activation energy for such process can be expressed as $\Delta H=\Delta H_{\mathrm{j}}+\Delta H_{\mathrm{GB}}$, where $\Delta H_{\mathrm{j}}$ and $\Delta \mathrm{H}_{\mathrm{GB}}$ are the activation enthalpies for the jog formation and the grain boundary diffusion, respectively. The activation enthalpy for grain boundary diffusion in the coarse grained magnesium is $0.95 \mathrm{eV}$ (Frost \& Ashby, 1982). Comparing with the estimated activation enthalpy value of $1.77 \mathrm{eV}$, the possible jog formation energy should be approximately $0.8 \mathrm{eV}$, which seems to be a reasonable value. Taking into consideration that the surface of grains was passivated during the milling by $1 \%$ of oxygen in a protective argon atmosphere; therefore, $\mathrm{MgO}$ particles in the grain boundaries may influence the grain boundary diffusion characteristics.

\section{Acknowledgements}

Z.T. and P.L. are grateful for the financial support to the Czech Grant Agency under the contract P108/12/J018.

\section{Author details}

Zuzanka Trojanová ${ }^{1}$, Pavel Lukáč ${ }^{1}$, Zoltán Száraz² and Zdeněk Drozd ${ }^{1}$

1 Charles University in Prague, Czech Republic

2 The University of Manchester, UK 


\section{References}

[1] Andersson, P., Cáceres, C.H. \& Koike, J. (2003) Hall-Petch parameters for tension and compression in cast Mg. Mater. Sci. Forum 419-42, 123-128. ISSN: $1662-9752$

[2] Chawla, K.K. (1991) Metal matrix composites. VCH Weinheim, ISBN: 03872-85679

[3] Arsenault, R.J. \& Shi, N. (1986). Dislocation generation due to differences between the coefficients of thermal expansion. Mater. Sci. Eng., 81, 175-187. ISSN: 0254-0584.

[4] Choi, H.J., Kim, Y., Shin, J.H. \& Bae, D.H. (2010) Deformation behavior of magnesium in the grain size spectrum from nano- to micrometer. Mater. Sci. Eng. A 527, 1565-1570. ISSN: 0254-0584.

[5] Couret, A. \& Caillard, D. (1985a) An in situ study of prismatic glide in magnesium I. The rate controlling mechanism. Acta Metall. 33 1447-1454. ISSN: 0921-5093

[6] Courret, A. \& Caillard, D. (1985b) An in situ study of prismatic glide in magnesiumII. Microscopic activation parameters, Acta Metall. 33, 1455-1462. ISSN: 0921-5093

[7] Dieringa, H. (2011) Properties of magnesium alloys reinforced with nanoparticles and carbon nanotubes: a review. J. Mater. Sci. 46, 289-306. ISSN: 0022-2461

[8] Dragomir, I.C. \& Ungár, T. (2002) The contrast factors of dislocations in the hexagonal crystal system. J. Appl. Cryst. 35, 556-564.

[9] Dunand, D.C. \& Mortensen, A. (1991) On plastic relaxation of thermal stresses in reinforced metals. Acta Metall. Mater. 39, 127-139. ISSN: 0921-5093

[10] Estrin, Y. \& Vinogradov A. (2013) Acta Mater. 61, 782-817. ISSN: 0921-5093

[11] Ferkel, H. (2003) Properties of graphite-strengthened magnesium. Adv. Eng. Mater. 5, 886-889. ISSN: 1527-2648

[12] Ferkel, H. \& Mordike, B.L. (2001) Magnesium strengthened by SiC nanoparticles. $\mathrm{Ma}$ ter. Sci. Eng. A 298, 193-199. ISSN: 0254-0584

[13] Frost, H.J. \& Ashby, M. F., Deformation-mechanism maps. Pergamon Press, Oxford, UK, 1982, 44. ISBN 0-08-029337-9

[14] Granato, A.V. \& Lücke, K. (1981) Temperature dependence of amplitude-dependent dislocation damping' J. Appl. Phys., 52, 7136-7142. ISSN 0021-8979

[15] Ion, S.E., Humphrey, F.J. \& White, S.H. (1982) Dynamic recrystallization and the development of microstructure during hot deformation of magnesium. Acta Met. 30, 1909-1919. ISSN: 0921-5093

[16] Kê, T.S. (1947) Experimental evidence of the viscous behaviour of grain boundaries in metals Phys. Rev. 71, 533-546. 1050-2947

[17] Koike, T., Kobayashi, T., Mukai, T., Watanabe, T.H., Suzuki, M., Maruyama, K. \& Higashi, K. (2003) The activity of non-basal slip systems and dynamic recovery at room 
temperature in fine-grained AZ31B magnesium alloys. Acta Mater. 51, 2055-2065. ISSN: 0921-5093

[18] Kužel, R. \& Klimanek, P. (1988) X ray diffraction line broadening due to dislocations in non-cubic materials. 2. The case of line anisotropy applied to hexagonal crystals. J. Appl.Cryst. 21, 363-368. ISSN: 0021-8898

[19] Kužel, R. (1998) DIFPATAN-Program for Powder Pattern Analysis. http:// www.xray.cz/ecm-cd/soft/xray/indexdifp.html

[20] Lakki, A., Schaller, R., Carry, C. \& Benoit, W. (1998) High temperature anelastic and viscoplastic deformation of fine-grained $\mathrm{MgO}$-doped $\mathrm{Al}_{2} \mathrm{O}_{3}{ }^{\prime}$, Acta Mater., 46, 689-700. ISSN: 0921-5093

[21] Langdon, T.G. (1994) A unified approach to grain boundary sliding and superplasticity. Acta Metall. Mater. 42, 2437-2443. ISSN: 0921-5093

[22] Lukáč, P., Trojanová, Z., Száraz, Z., Svoboda, M. \& Ferbl, H. (2006) Deformation behaviour of ultrafine grained magnesium with 3 vol. \% graphite. Z. Metallkd. 97, 344-349. ISSS: 1862-5282

[23] Mabuchi, M. \& Higashi, K. (1999) On accommodation helper mechanisms for superplasticity in metal matrix composites. Acta Mater. 47, 1915-1922. ISSN: 0921-5093

[24] Mabuchi, M., Chino, Y., Iwasaki, H., Aizawa, T. \& Higashi, K. (2001) The grain size and texture dependence of tensile properties in extruded Mg-9Al-1Zn. Mater. Trans. 42, 1182-1189. ISSN: 1345-9678

[25] Máthis, K., Nyilas, K., Axt, A., Dragomir-Cernatescu, I., Ungár, T. \& Lukáč, P. (2004) The evolution of non-basal dislocations as a function of deformation temperature in pure magnesium determined by X-ray diffraction, Acta Mater., 52, 2889-2894. ISSN: 0921-5093

[26] Máthis, K., Čapek, J., Zdražilová, Z. \& Trojanová, Z. (2011) Investigation of tensioncompression asymmetry of magnesium by use of the acoustic emission technique. Mater. Sci. Eng. A 528, 5904-5907. ISSN: 0254-0584

[27] Mohamed, F.A. (2003) A dislocation model for the minimum grain size obtainable by milling. Acta Mater. 51, 4107-4119. ISSN: 0921-5093

[28] Moll, F., Chmelík, F., Lukáč, P., Mordike, B.L. \& Kainer, K.U. (2000) Creep behaviour of a QE22-SiC particle reinforced composite investigated by acoustic emission and scanning electron microscopy. Mater. Sci. Eng. A 291, 246-249. ISSN: 0254-0584

[29] Naser, J., Riehemann, W. \& Ferkel, H. (1997) Dispersion hardening of metals by nanoscaled ceramic powders. Mater. Sci. Eng. A 234-236, 467-469. ISSN: 0254-0584

[30] Nayeb-Hashemi, A.A., Clark, J.B., \& Pelton A.D. The Li-Mg (Lithium-Magnesium) system, Bulletin of Alloy Phase Diagrams, 5, 365-374, 1984. ISSN: 1054-9714 
[31] Nes, E., Holmedal, B., Evangelista, E. \& Marthinsen, K. (2005) Modelling grain boundary strengthening in ultra-fine aluminium alloys', Mater. Sci. Eng. A, 410-411, 178182. ISSN: 0254-0584

[32] Nowick, A.S. \& Berry, B.S. (1972) Anelastic Relaxations in Crystalline Solids Academic Press, New York/London. ISBN: 70-154378

[33] Száraz, Z.. Trojanová, Z., Cabbibo, M., \& Evangelista, E. (2007) Strengthening in a WE54 magnesium alloy containing SiC particles. Mater. Sci. Eng. A, 462, 225-229. ISSN: 0254-0584

[34] Thostenson, E.T., Li, C. \& Chou, T.-W. (2005) Nanocomposites in context. Compos. Sci. Technol. 65, 491-516. ISSN: 0266-3538

[35] Trojanová, Z., Lukáč, P., Ferkel, H., Mordike, B.L. \& Riehemann, W. (1997) Stability of microstructure in magnesium reinforced by nanoscaled alumina particles. Mater. Sci. Eng. A 234-236, 798-801. ISSN: 0254-0584

[36] Trojanová, Z, Száraz, Z., Mielczarek, A, Lukáč, P. \& Riehemann, W. (2008) Plastic and fatigue behaviour of ultrafine-grained magnesium. Mater. Sci. Eng. A 483-484, 477-480. ISSN: 0254-0584

[37] Trojanová, Z., Máthis, K., Lukáč, P., Németh, G. \& Chmelík, F. (2011) Internal stress and thermally activated dislocation motion in an AZ63 magnesium alloy. Mater. Chem. Phys. 130, 1146-1150. ISSN: 0254-0584.

[38] Ungár, T. \& Borbely, A. (1996) The effect of dislocation contrast on X-ray line broadening: a new approach to line profile analysis. Appl. Phys. Let.; 69, 3173-3175. ISSN: 0003-6951

[39] Wilkens, M. (1970) 'The determination of density and distribution of dislocations indeformed single crystals from broadened X-ray diffraction profiles, phys. stat. sol. (a), 2, 359-370. ISSN: 1862-6319

[40] Yoo, M.H., Agnew, S.R., Morris, J.R. \& Ho, K.M. (2001) Non-basal slip systems in HCP metals and alloys: source mechanisms. Mater. Sci. Eng. A, 319-321, 87-92 ISSN: 0254-0584

[41] Zhang, J., Perez, R.J., Wong, C.R. \& Lavernia, E.J. (1994a) Effects of secondary phases on the damping behaviour of metals, alloys and metal matrix composites. Mater. Sci. Eng. R13, 325-390. ISSN: 0254-0584

[42] Zhang, J., Perez, R.J. \& Lavernia, E.J. (1994b) Effect of SiC and graphite particulates on the damping behavior of metal matrix composites. Acta Metal. Mater., 42, 395-409. ISSN: 0921-5093 
